\title{
Conditions for the occurrence of acicular ferrite transformation in HSLA steels
}

\author{
H. Zhao ${ }^{1,2}$, B. P. Wynne ${ }^{1}$, and E. J. Palmiere ${ }^{1, *}$ \\ ${ }^{1}$ Department of Materials Science and Engineering, The University of Sheffield, Sir Robert Hadfield Building, Mappin Street, \\ Sheffield S1 3JD, UK \\ ${ }^{2}$ Hebei Iron and Steel Group Technology Research Institute, No.385, Tiyu South Street, Shijiazhuang 050021, Hebei, China
}

Received: 21 June 2017

Accepted: 30 October 2017

Published online:

9 November 2017

(C) The Author(s) 2017. This article is an open access publication

\begin{abstract}
For the class of steels collectively known as high strength low alloy (HSLA), an acicular ferrite (AF) microstructure produces an excellent combination of strength and toughness. The conditions for the occurrence of the AF transformation are, however, still unclear, especially the effects of austenite deformation and continuous cooling. In this research, a commercial HSLA steel was used and subjected to deformation via plane strain compression with strains ranging from 0 to 0.5 and continuous cooling at rates between 5 and $50{ }^{\circ} \mathrm{C} \mathrm{s}^{-1}$. Based on the results obtained from optical microscopy, scanning electron microscopy and electron backscattering diffraction mapping, the introduction of intragranular nucleation sites and the suppression of bainitic ferrite $(\mathrm{BF})$ laths lengthening were identified as the two key requirements for the occurrence of AF transformation. Austenite deformation is critical to meet these two conditions as it introduces a high density of dislocations that act as intragranular nucleation sites and deformation substructures, which suppress the lengthening of BF laths through the mechanism of mechanical stabilisation of austenite. However, the suppression effect of austenite deformation is only observed under relatively slow cooling rates or high transformation temperatures, i.e., conditions where the driving force for advancing the transformation interface is not sufficient to overcome the austenite deformation substructures.
\end{abstract}

\section{Introduction}

In HSLA steels, acicular ferrite (AF) is defined as a highly substructured, non-equiaxed ferrite that forms on continuous cooling [1]. Despite the fact that the strengths of $\mathrm{AF}$ dominant microstructures are very close to those of BF dominant microstructures [2-4], these microstructures are named as AF separately because AF microstructures are relatively chaotic arranged and irregularly shaped in contrast to the highly organised and aligned bainitic ferrite (BF) microstructure which contains packets of parallel laths [5].

Address correspondence to E-mail: e.j.palmiere@sheffield.ac.uk 
It should be pointed out that, besides HSLA steels, the term "acicular ferrite" has also been used to describe a particular microstructure in steel welds. In steel welds, AF laths nucleate on non-metallic inclusions which are point nucleation sties. In steel welds, it was found that AF laths emanate from these point nucleation sites and grow in many different directions [5], which is very different from the irregular grain shape and chaotic arrangement of AF in HSLA steels. Therefore, from the point of view of present authors, AF in steel welds and AF in HSLA steels are two different microstructures and the latter is the focus of this research.

AF dominant microstructures have a greater potential to improve the strength [5], toughness [5, 6], $\mathrm{H}_{2} \mathrm{~S}$ resistance [7] and fatigue behaviour [8] compared to a ferrite-pearlite microstructure through grain refinement, increased dislocation density and easily controlled precipitation [1]. Furthermore, the toughness associated with an AF microstructure is considerably higher than that of $\mathrm{BF}$, due to a higher density of high angle grain boundaries (HAGBs), which are capable of arresting cracks or deflecting their propagation directions [9].

Given the good property combination intrinsic with an AF microstructure, it is not surprising that HSLA steels with AF dominant microstructures have already been successfully applied in several major pipeline projects [10, 11]. However, some aspects about the AF transformation are still unclear, especially as related to its formation conditions, including the effects of austenite deformation and subsequent continuous cooling. For example, increasing austenite deformation $[4,9,12,13]$ has been shown to increase the AF fraction, while 'AF-like' microstructures are produced when continuously cooled without austenite deformation [14-17]. These observations are contradicted from research [18-20] which indicates that even after significant amounts of austenite deformation, the transformation product still consists of parallel BF laths and the typical AF microstructure is absent.

As for the influence of cooling rates, their effect on AF transformation is also under debate. For example, $\mathrm{AF}$ was found in the final microstructure with cooling rates below $10^{\circ} \mathrm{C} \mathrm{s}^{-1}$ [14], but $\mathrm{BF}$ has been shown to be dominant at a slower cooling rate $\left(5^{\circ} \mathrm{C} \mathrm{s}^{-1}\right)$ [19], and as the cooling rate rises to $35^{\circ} \mathrm{C} \mathrm{s}^{-1}$, the fraction of intragranularly nucleated $\mathrm{AF}$ laths is increased, due to the decreased transformation onset temperature and thus the increased thermodynamic driving force, which is supposed to promote the intragranular nucleation as expected by nucleation theory [21].

In order to make clear the conditions for the occurrence of AF in HSLA steels, in this research, a commercial HSLA steel which has been successfully utilised to build a API X80 pipeline project $[22,23]$ was utilised and subjected to austenite deformation and accelerated cooling with different deformation and cooling parameters. The transformed microstructures were characterised by optical microscopy (OM), scanning electron microscopy (SEM) and electron back-scattered diffraction (EBSD). Based on the characteristics of microstructural evolution, the conditions for AF transformation were proposed and the underlying mechanisms were elucidated.

\section{Experimental details}

To simulate the industrial rolling process, plane strain compression (PSC) tests were adopted and conducted on a HSLA steel with the following composition in wt \%: $0.045 \mathrm{C}-1.43 \mathrm{Mn}-0.14 \mathrm{Si}-0.09 \mathrm{Nb}-$ $0.21 \mathrm{Cr}-0.12 \mathrm{Ni}-0.21 \mathrm{Cu}-0.01 \mathrm{Ti}$ with a balance of Fe.

In order to fully dissolve $\mathrm{Nb}$ carbide or carbonitride precipitates and shorten the preheating time during PSC tests, all specimens were heated to $1250{ }^{\circ} \mathrm{C}$, held for $30 \mathrm{~min}$ with argon atmosphere protection, and water quenched to room temperature before PSC testing.

The thermomechanical processing route for the PSC testing is schematically illustrated in Fig. 1 with true strains indicated for each deformation process.

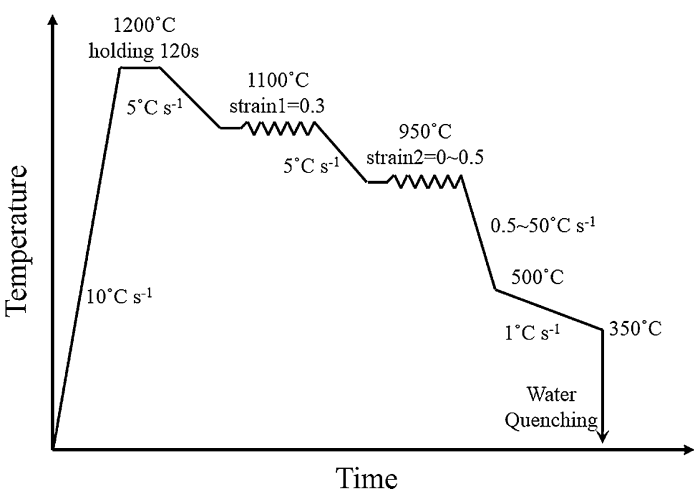

Figure 1 Schematic illustration of the thermomechanical testing profile. 
The as-heat treated and quenched samples were reheated to $1200{ }^{\circ} \mathrm{C}$ at a rate of $10{ }^{\circ} \mathrm{C} \mathrm{s}^{-1}$, held for 2 min for equilibration, and then cooled at a rate of $5{ }^{\circ} \mathrm{C} \mathrm{s}^{-1}$ to $1100{ }^{\circ} \mathrm{C}$ for a roughing deformation (strain1) of 0.3 at a constant true strain rate of $10 \mathrm{~s}^{-1}$. The samples were then cooled immediately to $950{ }^{\circ} \mathrm{C}$ at a rate of $5{ }^{\circ} \mathrm{C} \mathrm{s}^{-1}$ for the second deformation (strain2), with strain 2 varying between 0 and 0.5 . This second deformation was also performed at a constant true strain rate of $10 \mathrm{~s}^{-1}$ and was followed by accelerated cooling from 950 to $500{ }^{\circ} \mathrm{C}$ at rates between 5 and $50{ }^{\circ} \mathrm{C} \mathrm{s}^{-1}$, a slow cool from 500 to $350{ }^{\circ} \mathrm{C}$ at a rate of $1{ }^{\circ} \mathrm{C} \mathrm{s}^{-1}$, and finally a water quenching from $350{ }^{\circ} \mathrm{C}$ to room temperature. Furthermore, another three samples were also heat treated and deformed, but two of them were water quenched directly before strain 2 and after strain $2=0.5$ to examine the as-deformed austenite microstructure, while the remaining sample was continuously cooled after strain2 $=0.5-600{ }^{\circ} \mathrm{C}$ at a rate of $100{ }^{\circ} \mathrm{C} \mathrm{s}^{-1}$ followed with the slow cool and the water quenching as described above.

Samples with different cooling rates and strain $2=0$ were used to investigate the effect of cooling rates without austenite deformation, and samples with different amounts of strain $2(0-0.5)$ and the same cooling rate $\left(10{ }^{\circ} \mathrm{C} \mathrm{s}^{-1}\right)$ were used to investigate the effect of austenite deformation. Finally, samples with different cooling rate and the same strain $2=0.5$ were utilised to investigate the effect of cooling rates after a given amount of austenite deformation.

Specimens for metallographic observation were cut on the rolling direction-normal direction (RD-ND) plane and ground and polished carefully using standard procedures. A $2 \%$ nital etchant was used to reveal the transformed microstructures and saturated aqueous picric acid solution was used to reveal the prior-austenite grain boundaries (PAGBs). OM and SEM observations were carried out on Nikon Eclipse LV150 and JEOL JSM 6400, respectively.

To prepare specimens for EBSD mapping, after grinding and polishing, the specimens were then polished with a colloidal silica suspension for an additional 2 min. EBSD data acquisition was performed on the RD-ND plane of specimens in a FEI Sirion Field Emission Gun Scanning Electron Microscope with a step size of $0.2 \mu \mathrm{m}$ and accelerating voltage of $20 \mathrm{kV}$. To reduce the mis-indexing of phases in this complex microstructure, $\alpha$ iron was chosen as the only matching unit. Following a recommended method proposed in research [24], random noise points of the raw data were removed and non-indexed points were filled with the common orientations of their neighbours using HKL Channel 5 Tango software.

Besides microscopy, mechanical properties of the transformed products were characterised by Vickers microhardness with a $500 \mathrm{~g}$ applied load and $20 \mathrm{~s}$ dwelling time on a Mitutoyo hardness testing machine. Ten indentations were measured from each specimen.

\section{Results}

\section{Optical microstructure}

Optical micrographs depicting the PAGBs before strain 2 and after strain $2=0.5$ are shown in Fig. 2. In Fig. 2a, the austenite grains are fully recrystallised before strain 2 with an average linear intercept length of $37.0 \mu \mathrm{m}$ measured by the linear intercept method. In Fig. $2 b$, the austenite microstructure remains in an unrecrystallised condition indicating the experimental parameters chosen in this work are suitable to investigate the effect of accumulated strains in the austenite upon the subsequent transformation product.

Before the illustration of the transformed microstructure, it is necessary to describe the phase discrimination strategy used in this research. Firstly, phases transformed at different temperatures or with different transformation mechanisms have different defect densities and thus different microhardness. In research [25], microhardness values for different phases were provided for an ultra-low-carbon steel, HV140, HV175, HV220 and HV315 for polygonal ferrite (PF), quasi-polygonal ferrite $(\mathrm{QF}), \mathrm{BF}$ and martensite, respectively. Since AF has similar strength to that of $B F[2-4]$, the microhardness values of $\mathrm{AF}$ and $\mathrm{BF}$ should be comparable. So, there is a distinct difference between the microhardness values of $\mathrm{PF} / \mathrm{QF}$ and $\mathrm{AF} / \mathrm{BF}$ and Vickers microhardness values were used to determine whether the transformed microstructure is $\mathrm{PF} / \mathrm{QF}$ or $\mathrm{AF} / \mathrm{BF}$ dominant. Another way to determine whether a microstructure is $\mathrm{PF} / \mathrm{QF}$ or $\mathrm{AF} / \mathrm{BF}$ dominant depends on the distribution of disorientation angles. Since PF/QF grains usually do not have a near K-S OR with the prior- 

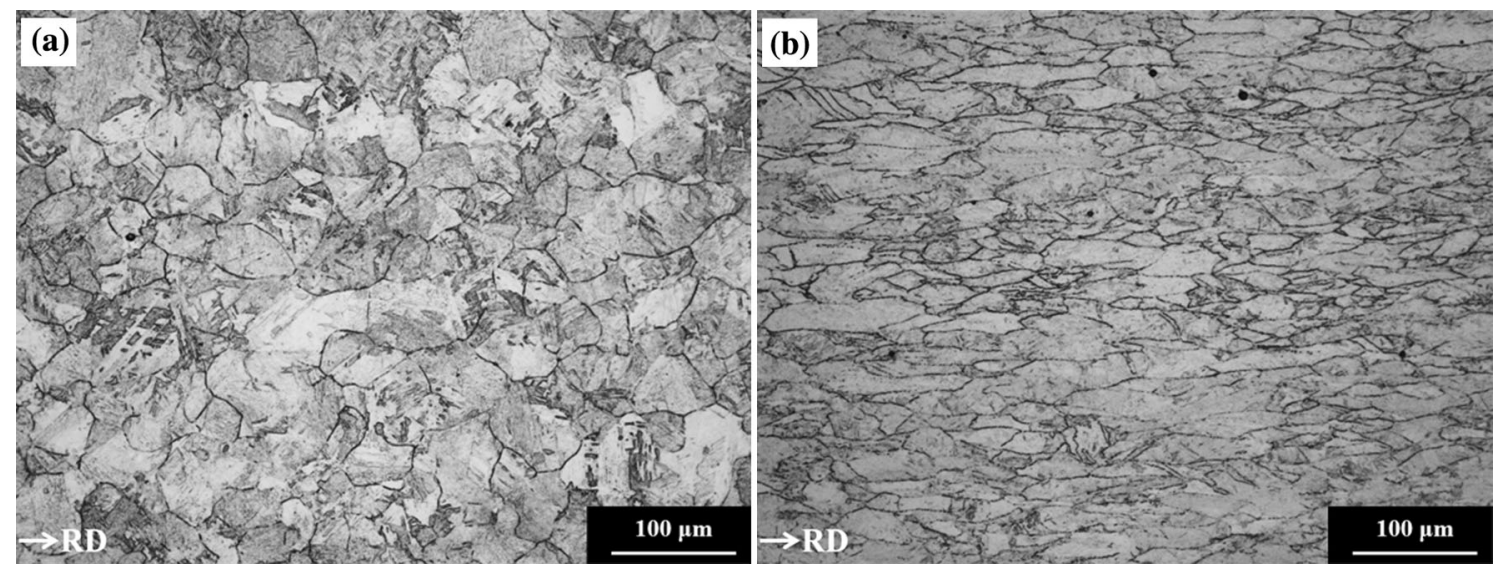

Figure 2 Optical micrographs depicting prior-austenite grain boundaries of water quenched samples: a after strain 1 of 0.3 and slow cooled to $950{ }^{\circ} \mathrm{C}$ and $\mathbf{b}$ after strain $2=0.5$.

austenite grains they grow into, the disorientation angle distribution of $\mathrm{PF} / \mathrm{QF}$ grains will be quite random and a high density of boundaries with disorientation angle between $21^{\circ}$ and $47^{\circ}$ exist $[26,27]$. While for displacive transformations, variants following a near K-S OR within the same prior-austenite grain do not have disorientation angles between $21^{\circ}$ and $47^{\circ}$, so for displacive transformation products, e.g. $\mathrm{AF}$ and $\mathrm{BF}$, the frequencies of disorientation angles between $21^{\circ}$ and $47^{\circ}$ should be significantly lower than others as reported in research [4, 27]. Therefore, the distribution of disorientation angles could also be used to differentiate $\mathrm{PF} / \mathrm{QF}$ and $\mathrm{AF} / \mathrm{BF}$ dominant microstructures. Secondly, AF and BF can be readily discriminated from each other by their morphological characteristics, chaotically arranged and irregularly shaped for AF and parallel and aligned for BF. It is also found that AF microstructures usually have a high density of high angle grain boundaries (HAGBs) [27, 28], while BF microstructures transformed at high temperatures or with slow cooling rates are lack of HAGBs [29]. In the end, it should be pointed out that the above-mentioned method only determines the dominant phases of the transformed microstructure and it is extremely difficult to determine whether a specific ferrite grain is $\mathrm{QF}$, AF or granular bainite (GB) by its morphology $[28,30]$. If a grain-level phase identification is required for HSLA steels, EBSD-based method can be resorted to $[27,28]$.

The optical micrographs of samples with different cooling rates and strain $2=0$ are shown in Fig. 3. In all microstructures, a parallel morphology of the transformed products can be clearly observed.
PAGBs remain, and the parallel laths developed from the PAGBs extended into the austenite grains, sometimes across the whole grain, which is a typical BF morphology. At the cooling rate of $5{ }^{\circ} \mathrm{C} \mathrm{s}^{-1}$, Fig. $3 \mathrm{a}$, the microstructure contains some aggregates of BF laths with an almost entirely granular aspect with the boundaries between these laths not very clear. This kind of microstructure is usually termed as granular bainite (GB) $[5,31]$. At the cooling rate of $50{ }^{\circ} \mathrm{C} \mathrm{s}^{-1}$, Fig. $3 \mathrm{~d}$, the BF laths have become thinner and the boundaries between them can be seen clearly, which is often classified as lath bainite (LB) [32]. With cooling rates increasing from 10 to $20^{\circ} \mathrm{C} \mathrm{s}^{-1}$, a gradual microstructure change from GB to $\mathrm{LB}$ is observed as shown in Fig. 3b, c. Despite the difference in morphology, it has been suggested that GB is not different from LB in terms of transformation mechanism, and that both consist of packets with laths containing high dislocation densities [5]. Therefore, in this work, both GB and LB are classified as $\mathrm{BF}$ and that $\mathrm{BF}$ obviously dominates the microstructures cooled at $5-50{ }^{\circ} \mathrm{C} \mathrm{s}^{-1}$ without prioraustenite deformation.

The optical micrographs of the samples cooled at $10^{\circ} \mathrm{C} \mathrm{s}^{-1}$ with various strain2 from 0 to 0.5 are shown in Fig. 4. The microhardness values for the microstructures shown in Fig. $4 \mathrm{a}-\mathrm{d}$ are $207.0 \pm 2.5$, $208.4 \pm 2.6,213.1 \pm 2.3$ and $222.1 \pm 2.8$ (HV0.5/20), respectively, with errors standing for the confidence limits, suggesting that the transformed microstructures are AF/BF dominant. In Fig. $4 a$, b, both of the ferrite grains of the transformed microstructures have a clear parallel morphology and thus are classified as BF dominant microstructures. The similarity of these 

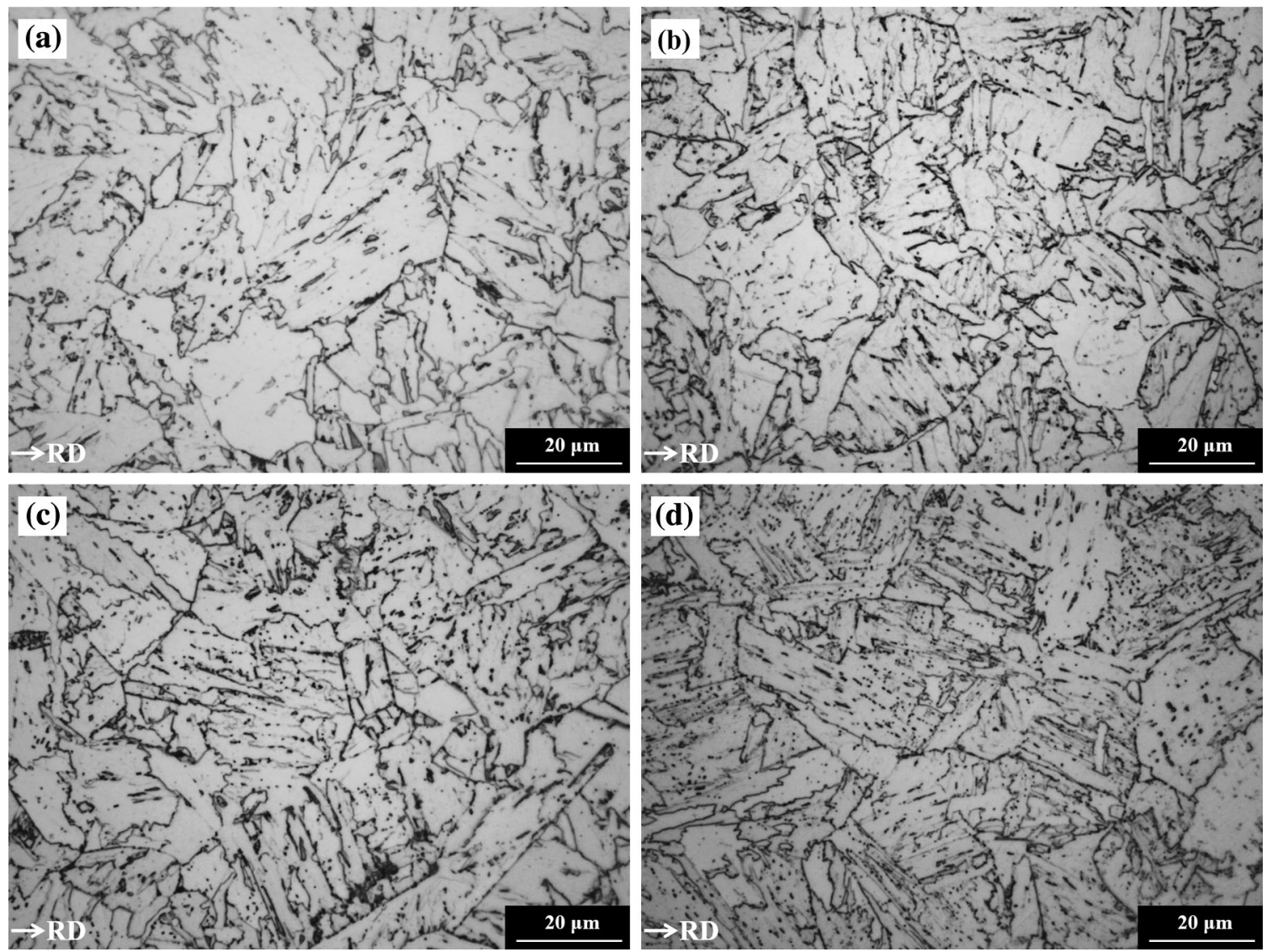

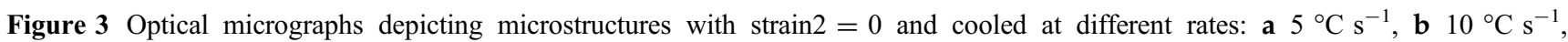
c $20^{\circ} \mathrm{C} \mathrm{s}^{-1}$ and $\mathrm{d} 50{ }^{\circ} \mathrm{C} \mathrm{s}^{-1}$.

two micrographs means that a small amount of austenite deformation (strain $2=0.1$ ) has very little influence on the transformed microstructure. With an increase in strain2 (Fig. 4c, d), the microstructure becomes finer, and the parallel $\mathrm{BF}$ laths get shorter. The fraction of parallel BF laths is gradually reduced; replaced by non-equiaxed ferrite lathes with a chaotic arrangement, which is a typical AF morphology. It is clear from Fig. 4a-d that the AF fraction increases with strain2 and a transition from $\mathrm{BF}$ to AF occurs.

Additionally, throughout all the micrographs, fine martensite/retained austenite (M/A) constituents can be found within the matrix, dark under OM observation and white under SEM observation [33]. The formation of this microphase can be attributed to the partitioning of carbon from ferrite laths to the surrounding austenite during transformation [17]. The shape of the M/A constituents also changes with the increased strain2, from elongated rods in Fig. 4a, $\mathrm{b}$ to small equiaxed particles in Fig. $4 \mathrm{c}$, d.
The optical micrographs of samples with different cooling rates $\left(5,10,20\right.$ and $\left.50{ }^{\circ} \mathrm{C} \mathrm{s}^{-1}\right)$ and strain $2=0.5$ are shown in Fig. 5. The microhardness values for the microstructures shown in Fig. 5a-d are $215.6 \pm 2.1,222.1 \pm 2.8,223.6 \pm 2.6$ and $238.0 \pm 2.2$ (HV0.5/20), respectively, with errors standing for the confidence limits, suggesting that the transformed microstructures are also AF/BF dominant. In Fig. 5a$\mathrm{C}$, with cooling rates between 5 and $20{ }^{\circ} \mathrm{C} \mathrm{s}^{-1}$, the microstructures mainly consist of AF laths together with a small fraction of polygonal ferrite (PF) or quasi-polygonal ferrite (QF) grains at the lower cooling rate $\left(5^{\circ} \mathrm{C} \mathrm{s}^{-1}\right)$ and parallel $\mathrm{BF}$ laths at the higher cooling rates $\left(10-20{ }^{\circ} \mathrm{C} \mathrm{s}^{-1}\right)$. These parallel BF laths may not be clear in these optical micrographs, but the SEM micrographs with higher magnification in the following section prove their existence. Increasing the cooling rate further to $50{ }^{\circ} \mathrm{C} \mathrm{s}^{-1}$, a parallel morphology of the transformed product becomes evident and many laths are produced across a whole austenite grain, which is typical for BF 

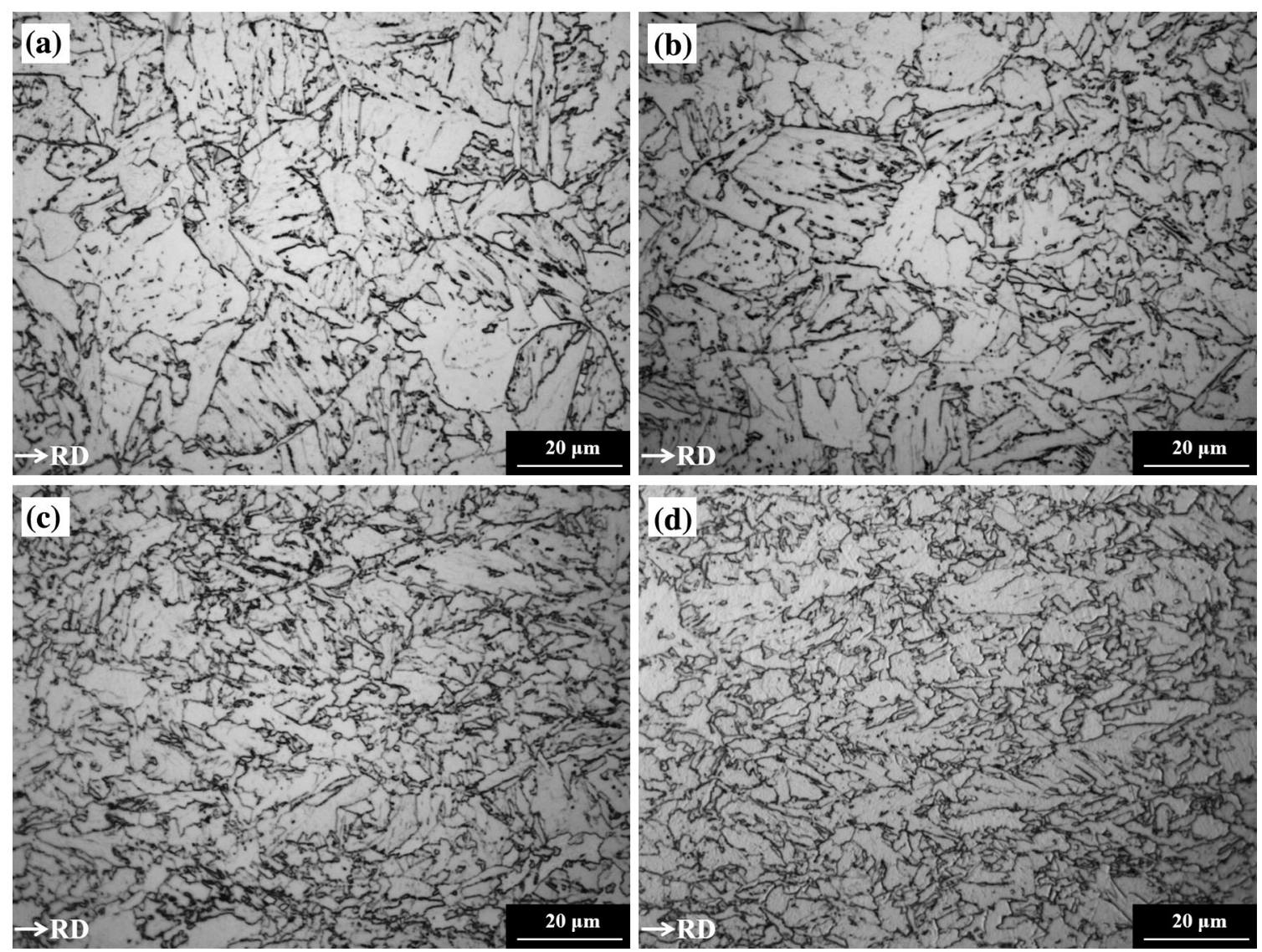

Figure 4 Optical micrographs depicting microstructures cooled at $10{ }^{\circ} \mathrm{C} \mathrm{s}^{-1}$ after various strain2: a $0, \mathbf{b} 0.1, \mathbf{c} 0.3$ and $\mathbf{d ~} 0.5$.

dominant microstructures. In Fig. $5 b-d$, it is interesting to notice that the fraction of BF increases with increasing cooling rate, which means under the same austenite deformation condition (strain $2=0.5$ ), a transition from $\mathrm{AF}$ to $\mathrm{BF}$ occurs with an associated increase in cooling rate.

\section{Microstructure under SEM}

Since BF dominates in the microstructures cooled at $5-50{ }^{\circ} \mathrm{C} \mathrm{s}^{-1}$ without austenite deformation, and the transition between $\mathrm{AF}$ and BF mainly happens with austenite deformation, the following microstructure characterisation in this research mainly focuses on the samples with austenite deformation.

To observe the microstructure in greater detail, SEM secondary electron micrographs of the transformed microstructures cooled at $10{ }^{\circ} \mathrm{C} \mathrm{s}^{-1}$ with various strain 2 from 0 to 0.5 are shown in Fig. 6. In Fig. $6 \mathrm{a}-\mathrm{d}$, when strain 2 is increased from 0 to 0.5 , similar microstructure characteristics to those revealed by $\mathrm{OM}$ are observed. Non-equiaxed ferrite laths with an irregular arrangement gradually replaces parallel $\mathrm{BF}$ laths and the lengths of $\mathrm{BF}$ laths are shortened with increased strain2.

SEM secondary electron micrographs of the transformed microstructures cooled at rates between 5 and $50{ }^{\circ} \mathrm{C} \mathrm{s}^{-1}$ with strain $2=0.5$ are shown in Fig. 7. In Fig. $7 \mathrm{a}-\mathrm{d}$, similar microstructural changes can be observed compared to optical micrographs as well. In Fig. $7 \mathrm{~b}, \mathrm{c}$, at the cooling rates of 10 and $20^{\circ} \mathrm{C} \mathrm{s}^{-1}$, although the dominant microstructure is $\mathrm{AF}$, some short parallel BF laths forming short wide packets along PAGBs can be seen in the microstructures, and between these wide packets, AF microstructure exists. This actually is an important characteristic of the AF dominant microstructure and this will be discussed in "Transition from AF to $\mathrm{BF}^{\prime}$ section. Finally, increasing the cooling rate further to $50{ }^{\circ} \mathrm{C} \mathrm{s}^{-1}$, a parallel morphology of the transformed product becomes dominant and can be seen clearly in Fig. 7d and many laths extended across the whole austenite grains. 

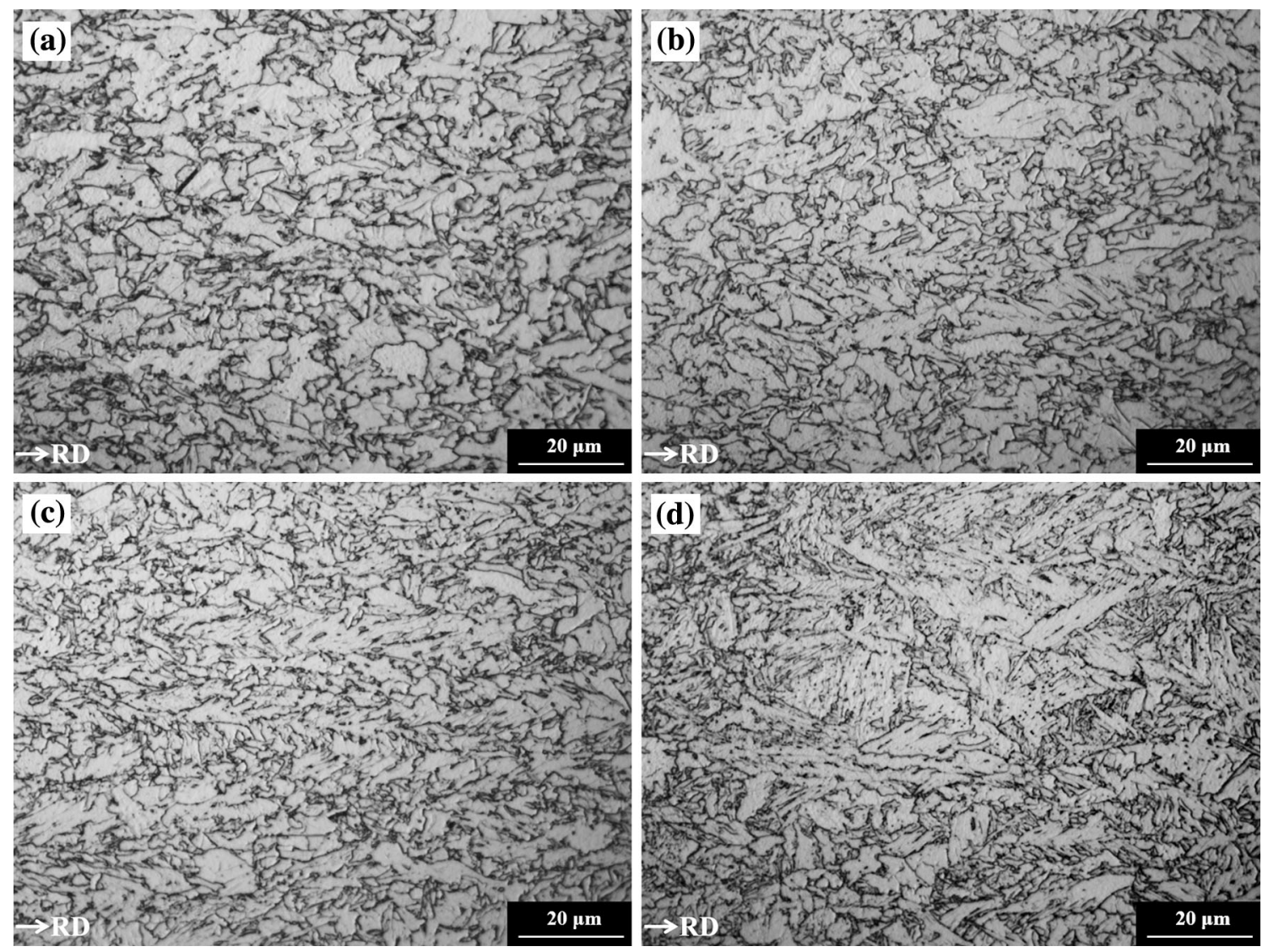

Figure 5 Optical micrographs depicting microstructures cooled at rates between 5 and $50{ }^{\circ} \mathrm{C} \mathrm{s}^{-1}$ after strain 2 of 0.5 : a $5{ }^{\circ} \mathrm{C} \mathrm{s}{ }^{-1}$, b $10{ }^{\circ} \mathrm{C}$ $\mathrm{s}^{-1}, \mathrm{c} 20{ }^{\circ} \mathrm{C} \mathrm{s}^{-1}$ and $\mathrm{d} 50{ }^{\circ} \mathrm{C} \mathrm{s}{ }^{-1}$.

\section{EBSD mapping}

Following noise reduction, a small area of each data set was used to plot an inverse pole figure (IPF) coloured orientation map and a corresponding boundary map. For a statistical analysis of the boundary interception length, each whole data set was used.

The selected area IPF coloured orientation maps and boundary maps of the transformed microstructures of samples cooled at $10{ }^{\circ} \mathrm{C} \mathrm{s}^{-1}$ with various strain2 from 0 to 0.5 are shown in Fig. 8. In Fig. 8e, both the densities of high angle grain boundary (HAGB) and low-angle grain boundary (LAGB) are very low. The adjacent laths with disorientations below $15^{\circ}$ make up the so-called effective grains [12]. Adjacent BF laths usually have similar orientations, thus forming coarse effective grains enclosed by HAGBs. With the increase in strain2 from 0 to 0.5 , densities of HAGB and LAGB both are increased significantly as shown in Fig. 8e-h. The coarse effective grains composed of parallel laths in Fig. 8a, b are replaced gradually by very fine effective grains of $\mathrm{AF}$ laths in Fig. 8c, d. The increased amount of effective grains means the nucleation sites increase with strain2.

Although refined AF microstructures are dominant in Fig. 8c, d, some coarse packets identified by black arrows can still be seen, indicating the existence of $\mathrm{BF}$ laths, which corresponds well with the microstructures shown in Fig. 6c, d.

The selected area IPF coloured orientation maps and boundary maps of the transformed microstructures of samples with strain $2=0.5$ at various cooling rates between 5 and $50{ }^{\circ} \mathrm{C} \mathrm{s}^{-1}$ are shown in Fig. 9 . The density and fraction of LAGB increases constantly with increasing cooling rate as seen in Fig. 9eh. Coarse effective grains identified by black arrows can be found within all the microstructures in Fig. 9. Therefore, all the microstructures can be divided into two parts, coarse effective grains composed of parallel BF laths and fine effective grains mainly composed of AF laths with an irregular arrangement. 

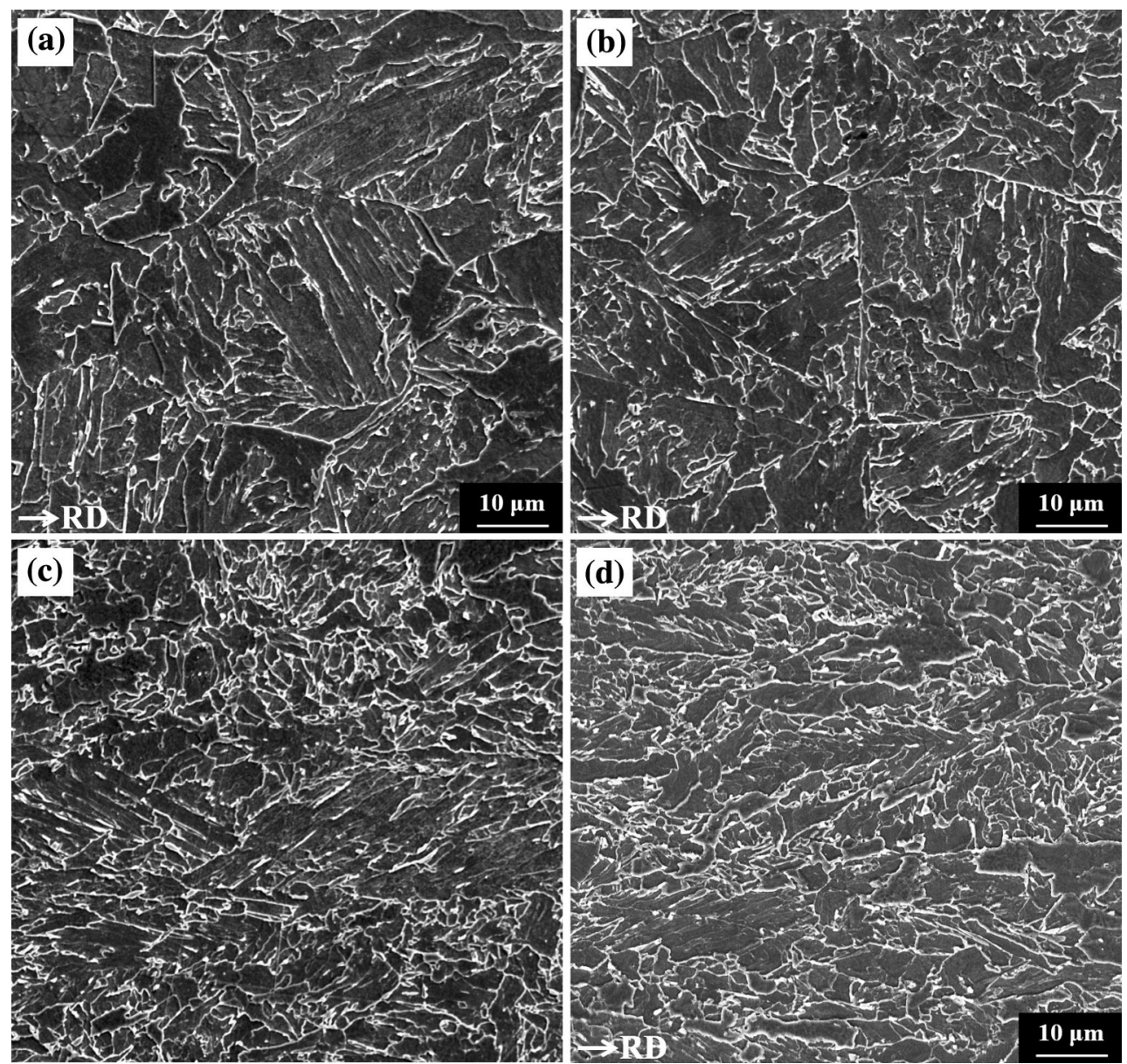

Figure 6 SEM secondary electron micrographs showing microstructures cooled at $10{ }^{\circ} \mathrm{C} \mathrm{s}^{-1}$ after various strain2: a $0, \mathbf{b} 0.1, \mathbf{c} 0.3$ and d 0.5 .

From Fig. 9a, b, the density of HAGBs is increased because the relatively coarse PF/QF grains in Fig. 9a are replaced by fine AF laths in Fig. 9b. Raising the cooling rate from 10 to $50{ }^{\circ} \mathrm{C} \mathrm{s}^{-1}$, the area of coarse effective grains increases, leading to a quite inhomogeneous microstructure at the cooling rate of $50{ }^{\circ} \mathrm{C} \mathrm{s}^{-1}$. The increase in the coarse effective grain area fraction suggests that a transition from $\mathrm{AF}$ to $\mathrm{BF}$ happens. Furthermore, the change of the density of effective grains implies differences in nucleation sites density at various cooling rates.

According to the microstructures in Figs. 8 and 9, the differences in austenite deformation and cooling rates leads to the changes in microstructure refinement. Disorientation threshold values of $4^{\circ}$ and $15^{\circ}$ are typical threshold values to define the grain size for strengthening and toughening, respectively $[34,35]$. Low-angle disorientation $\left(4^{\circ}\right)$ grain size is one of the factors that controls the yield strength of steel as boundaries with disorientation angles above this value are expected to be able to oppose dislocation movement, while HAGBs with disorientation angles higher than $15^{\circ}$ provide effective barriers to cleavage fracture $[34,36]$.

Grain sizes defined by the different disorientation threshold values, $4^{\circ}$ and $15^{\circ}$ were measured by the linear intercept method using the Channel 5 software, respectively. The geometric mean values of the linear intercept lengths in both horizontal and vertical directions were calculated in Ref. [24] and are shown in Fig. 10.

In Fig. 10a, the grain sizes following both disorientation threshold values decreases with the rise of strain 2 and the grain size range is very similar to which found in Ref. [35]. Furthermore, the differences between samples with strain $2=0.1-0.5$ are statistically significant as there are no overlaps of their $95 \%$ CL error bars. The error bars also become shorter as 

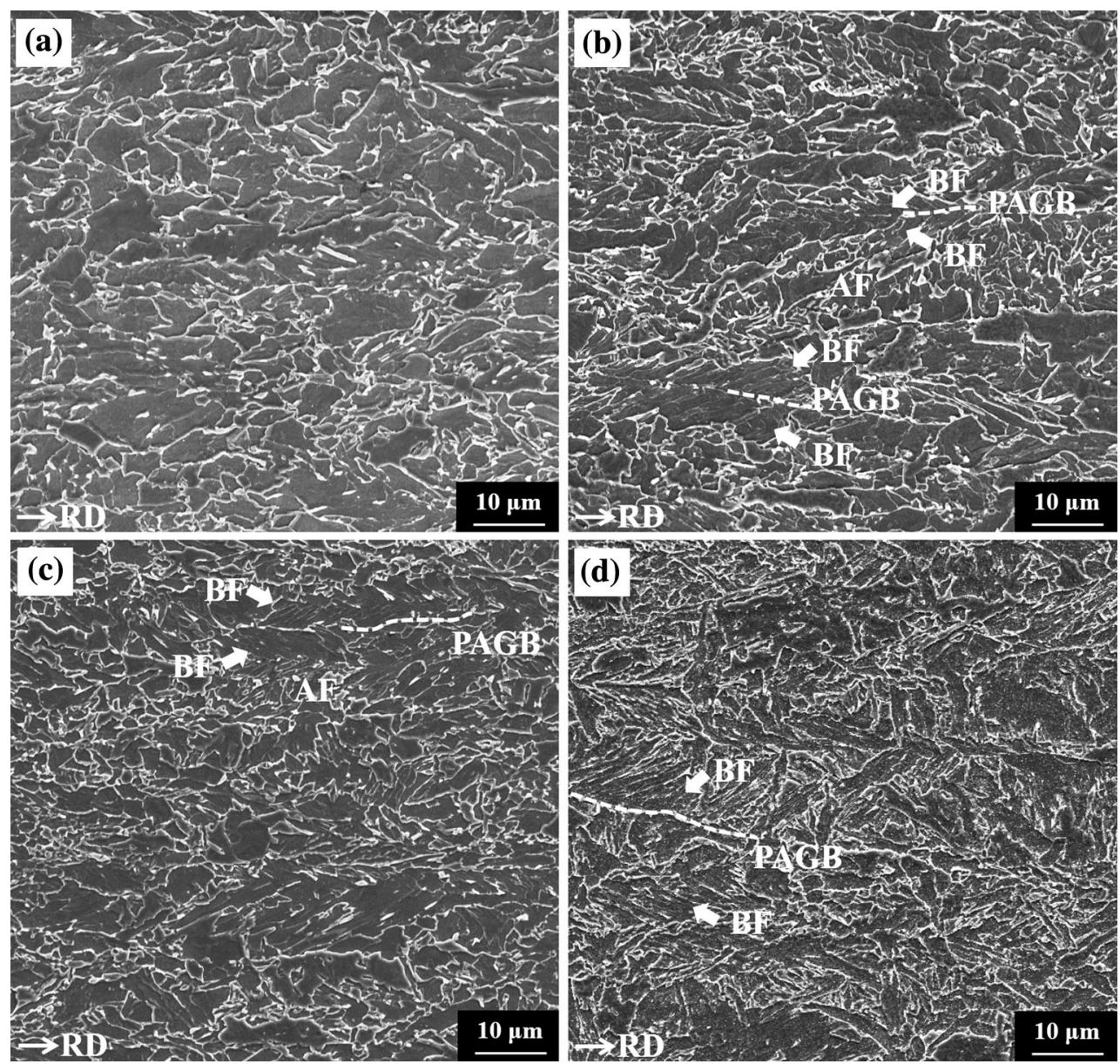

Figure 7 SEM secondary electron micrographs showing the microstructures cooled at rates between 5 and $50{ }^{\circ} \mathrm{C} \mathrm{s}^{-1}$ after strain2 of 0.5 : a $5^{\circ} \mathrm{C} \mathrm{s}^{-1}$, b $10^{\circ} \mathrm{C} \mathrm{s}^{-1}$, c $20^{\circ} \mathrm{C} \mathrm{s}^{-1}$ and

d $50{ }^{\circ} \mathrm{C} \mathrm{s}^{-1}$, where white dashed lines represent the traces of the parent austenite grain boundaries.

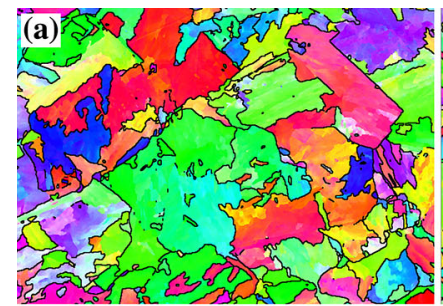

(e)

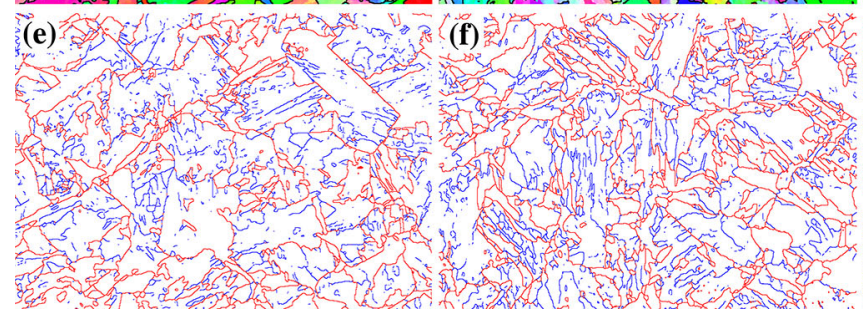

Figure 8 EBSD maps of the transformed microstructures after cooling $\left(10^{\circ} \mathrm{C} \mathrm{s}^{-1}\right)$ with various strain2: a-d inverse pole figure coloured orientation maps corresponding to microstructures with strain 2 of $0,0.1,0.3$ and 0.5 , respectively, where black lines represent high angle boundaries with disorientation no less than

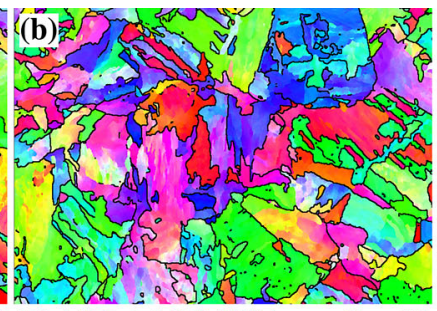

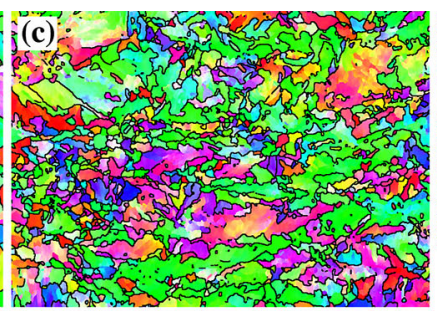
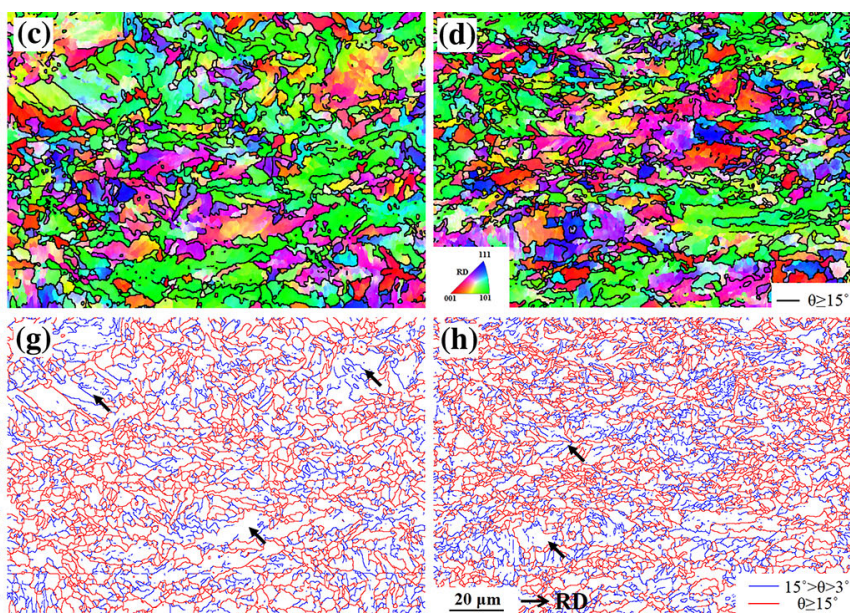

$15^{\circ}$; $\mathbf{e}-\mathbf{h}$ boundary maps corresponding to the same area in $\mathbf{a}-\mathbf{d}$, respectively, where blue lines represent low-angle boundaries with disorientation between $3^{\circ}$ and $15^{\circ}$, while red lines represent high angle boundaries with disorientation no less than $15^{\circ}$. 

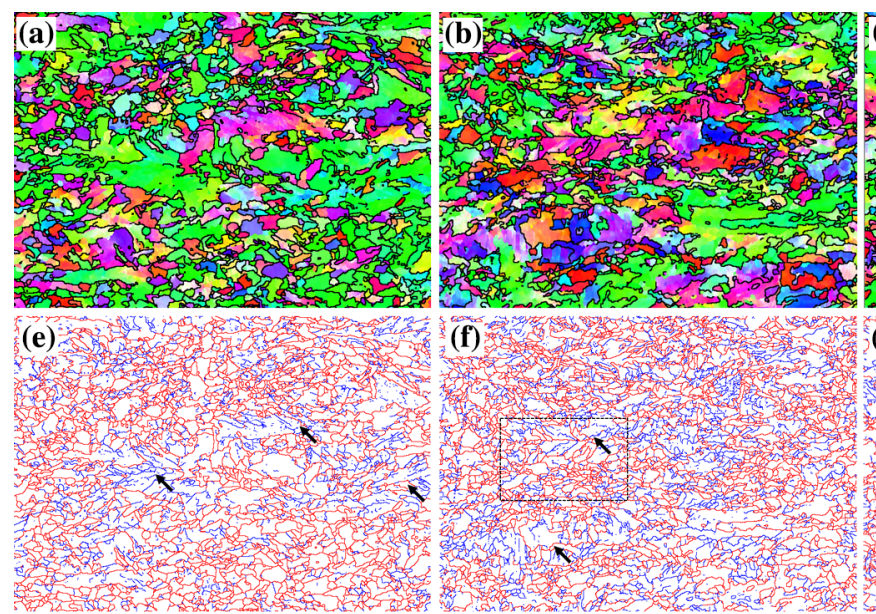
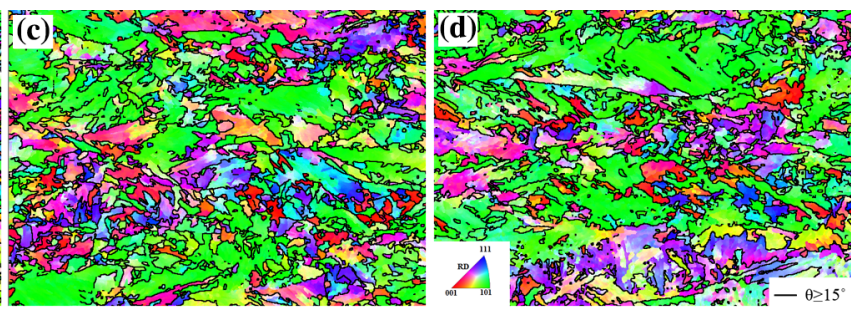

g) $1+2+25$

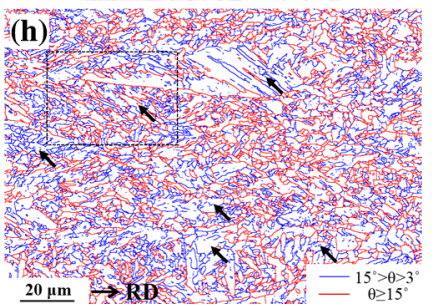

Figure 9 EBSD maps of the transformed microstructures cooled at different rates with strain 2 of 0.5 : $\mathbf{a}-\mathbf{d}$ inverse pole figure coloured orientation maps corresponding to microstructures with cooling rates of $5,10,20$ and $50{ }^{\circ} \mathrm{C} \mathrm{s}^{-1}$, respectively, where black lines represent high angle boundaries with disorientation no less than $15^{\circ} ; \mathbf{e}-\mathbf{h}$ boundary maps corresponding to the same area in $\mathbf{a}-\mathbf{d}$ respectively, where blue lines represent low-angle boundaries with disorientation between $\stackrel{\circ}{3}^{\circ}$ and $15^{\circ}$, while red lines represent high angle boundaries with disorientation no less than $15^{\circ}$.

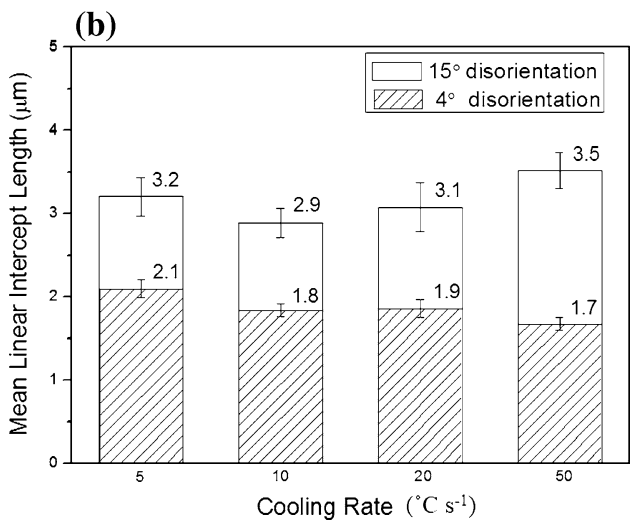

$10{ }^{\circ} \mathrm{C} \mathrm{s}^{-1}$ with strain 2 of $0,0.1,0.3$ and $0.5 ; \mathbf{b}$ microstructure with strain 2 of 0.5 cooled at rates of $5,10,20$ and $50{ }^{\circ} \mathrm{C} \mathrm{s}{ }^{-1}$, where error bars represent $95 \%$ confidence limits of the measurement.

\section{Discussion}

\section{Acicular ferrite transformation mechanism}

The transformation mechanism of AF is still controversial. By different researchers, it was suggested as being similar to various common microstructures in steels, including granular bainite (GB) [37], quasipolygonal ferrite (QF) [16, 38, 39], Widmanstätten ferrite (WF) [40] and bainitic ferrite (BF) [2, 3]. Differently, a mixture of these microstructures was regarded as $\mathrm{AF}$ in research $[35,41]$.

However, in our opinion, AF should be classified as a type of bainitic transformation product. This 
judgement is supported by many characteristics associated with the AF transformation and microstructure. For example, in an isothermal holding test [12], a transition from BF to AF occurs, which means that $\mathrm{AF}$ and $\mathrm{BF}$ transformations can proceed under the same thermodynamic conditions. Furthermore, when the AF transformation is nearly finished after long isothermal holding at $600{ }^{\circ} \mathrm{C}$, the final volume fraction of AF was only $51 \%$ [12], corresponding well to the incomplete transformation phenomenon of the bainitic transformation [5]. As for the microstructure characteristics, the lack of boundaries with disorientation angles between $21^{\circ}$ and $47^{\circ}$ in the AF microstructures [4, 27] suggests that AF holds a near Kurdjumov-Sachs (K-S) orientation relationship with the parent austenite, which means that the AF transformation is displacive. Additionally, it was found in many TEM observations that AF laths contain a higher density of dislocations than those associated with reconstructive transformation products [12, 42-44], and the AF microstructure consists of several parallel subunits with a size less than $1 \mu \mathrm{m}[12,42]$ resembling the sheaf morphology of bainitic ferrite [5]. In summary, AF shows similar transformation behaviours and microstructure characteristics to those of bainite; therefore, it is reasonable to say that the AF transformation mechanism is in fact bainitic, which is also agreed by many other researchers [2, 3, 12, 44-46].

\section{Transition from $\mathrm{BF}$ to $\mathrm{AF}$}

Although the AF transformation mechanism is bainitic, AF has a quite different morphology compared with that of BF. The formation of AF can be explained by the existence of intragranular nucleation sites introduced by the deformation of the austenite.

The nucleation process of bainite relates to the spontaneous dissociation of specific dislocations in the parent austenite [5], which was originally proposed for martensite nucleation by Olson and Cohen [47]. During nucleation, existing dislocations dissociate on the closest packed planes, forming groups of stacking faults, and these stacking fault groups become unstable and undergo a spontaneous transformation during cooling. The dislocations involved are glissile, so that this mechanism does not require the diffusion of lattice atoms, which corresponds well to the low transformation temperature of bainite and martensite at which thermal activation is in short supply [5]. Despite the similar nucleation mechanism between martensite and bainite, carbon partitioning is required during bainite nucleation to guarantee a reduction of free energy, due to the higher transformation temperature of bainite [5].

That martensite readily nucleates at densely stacked dislocation arrays has been widely accepted [48-51], and the potency of this nucleation site was proposed to be determined by the dislocation quantity in the array and the nucleus requires a critical quantity of dislocations inside to be sufficiently potent [52]. Therefore, besides austenite grain boundaries, where densely stacked dislocation arrays can be accommodated, intragranular dislocation arrays introduced by austenite deformation can also act as nucleation sites for the martensitic transformation. Furthermore, the strain field of a martensite lath may interact with the strain field of the intragranular nucleation site, a highly deformed region, so that the free energy barrier for the nucleation can decrease [53, 54]. More convincingly, martensite blocks were found developing from sub-grain boundaries introduced by austenite deformation through in situ laser scanning confocal microscopy technique [55].

Since the AF transformation mechanism is bainitic, the nucleation of AF should be similar to that of martensite with the additional requirement of carbon partitioning as illustrated above. It is reasonable to assume that densely stacked dislocation arrays introduced intragranularly by austenite deformation can act as nucleation sites for AF. Actually, the nucleation of $\mathrm{AF}$ has been found at various deformation substructures, like deformation bands $[9,13,56,57]$ and dislocation cell walls [58]. Therefore, despite a wide range of cooling rates used $\left(5-50{ }^{\circ} \mathrm{C} \mathrm{s}^{-1}\right)$ in this research, for samples undeformed (strain $2=0)$ or slightly deformed (strain2 $=0.1$ ), laths nucleated primarily on PAGBs where densely stacked dislocation arrays can be accommodated, and these laths finally developed into BF packets with a parallel morphology as shown in Figs. 3 and 4a, b. On the other hand, when the austenite is heavily deformed, a high density of dislocations were introduced into the austenite grains, and these dislocations acted as intragranular nucleation sites, leading to the intragranularly nucleated laths which finally developed into the AF dominant microstructures as shown in Figs. 4c, d and 5a-c. Therefore, as the strain 2 increased from 0 to 0.5 , a 
transition from BF to AF occurred, Fig. 4, highlighting the fact that austenite deformation is required for the AF transformation in HSLA steels.

AF laths nucleated intragranularly at deformation substructures do not develop into a parallel morphology on a large scale because the development of a parallel morphology is stifled by impingement between adjacently nucleated AF laths [5]. Actually, several adjacent parallel AF laths form a packet on a small scale and different packets have different lengthening directions [44]. AF packets will impinge with other packets formed at nearby nucleation sites, which prevents the formation of a general parallel morphology and brings about the irregular morphology of AF [44].

The transition from boundary nucleated $\mathrm{BF}$ to intragranularly nucleated AF leads to the increase in HAGB density, Fig. 8, and the reduction of effective grain size, Fig. 10a. During the bainite transformation, strong variant selection occurs and under relatively slow cooling rates or high transformation temperatures, variant selection mainly favours the variant pairs with low disorientation angles between them [29], resulting in the low HAGB density, Fig. 8e-f, and large effective grain size, Fig. 10a. However, for AF dominant microstructures, austenite deformation increases the intragranular nucleation sites, therefore, more laths nucleate directly at intragranular nucleation sites instead of sympathetically nucleating in the form of variant pairs. The formation of these intragranularly nucleated AF laths can weaken the variant selection mechanism [59], and thus more types of variants and thus boundaries can be generated in each austenite grain. Consequently, increasing the fraction of intragranularly nucleated AF by austenite deformation, higher density of HAGBs and smaller effective grain size can be obtained.

\section{Transition from AF to BF}

However, meeting the condition of introducing intragranular nucleation sites, the AF transformation does not necessarily happen as shown in Fig. $7 \mathrm{f}$ with a cooling rate of $50{ }^{\circ} \mathrm{C} \mathrm{s}^{-1}$. For this sample, a high density of intragranular nucleation sites had already been introduced into austenite by deformation (strain2 $=0.5$ ), but the transformation product still mainly consists of a typical BF dominant microstructure with a parallel morphology. In other words, intragranular nucleation sites are unable to induce the AF transformation at this high cooling rate. Therefore, there must be another condition needed for the occurrence of AF transformation.

To figure out this, one should pay attention to a feature common in Fig. $7 b$, c. In these AF dominant microstructures, there are some short parallel $\mathrm{BF}$ laths nucleated on PAGBs and stretched into austenite grains and these BF laths do not take up the whole austenite grain and the rest of the austenite grain develop into AF. While in the BF dominant microstructure, Fig. 7d, parallel BF laths extended from PAGBs and developed across the whole austenite grain or impinges with other BF laths. To further confirm these microstructural characteristics, two areas were selected from the EBSD maps as indicated by the black dashed blocks in Fig. 9f, h, respectively. All-Euler-angle coloured orientation maps of these two areas with black lines representing the boundaries with disorientation angles higher than 3 are shown in Figs. 11 and 12, respectively. Different parent austenite (PA) grains were separated from each other by carefully comparing the pole figure characteristics of different parts and PAGBs were highlighted by white dash lines in those figures. The validity of the separation of these PA grains can be proved by the good correspondence between the $\{100\}$ pole figures of the measured $\alpha$ iron orientations and those of the variant orientations of the calculated PA orientations. The method proposed in research [60] was used to evaluate these PA orientations following the Kurdjumov-Sachs (K-S) orientation relationship. Although Nishiyama-Wasserman (N-W) orientation relationship was also proposed as the orientation relationship, it was found that BFs are formed by satisfying near $\mathrm{K}-\mathrm{S}$ orientation relationship [61, 62]. Therefore, the K-S orientation relationship was used here.

In Fig. 12a where BF is the dominant microstructure, parallel BF laths forming packets with similar colours nucleated on PAGBs and extended across the whole grain or impinged with other BF packets. However, in Fig. 11a, parallel BF laths nucleated on PAGBs and extended into PA2 were stifled and the remaining austenite transformed into irregularly arranged AF laths, which corresponds very well to the characteristics observed in Fig. 7b, c. It is interesting to note that the more irregular the transformed microstructure, the more spreading of the $\alpha$ iron orientations in the pole figures. There are some 


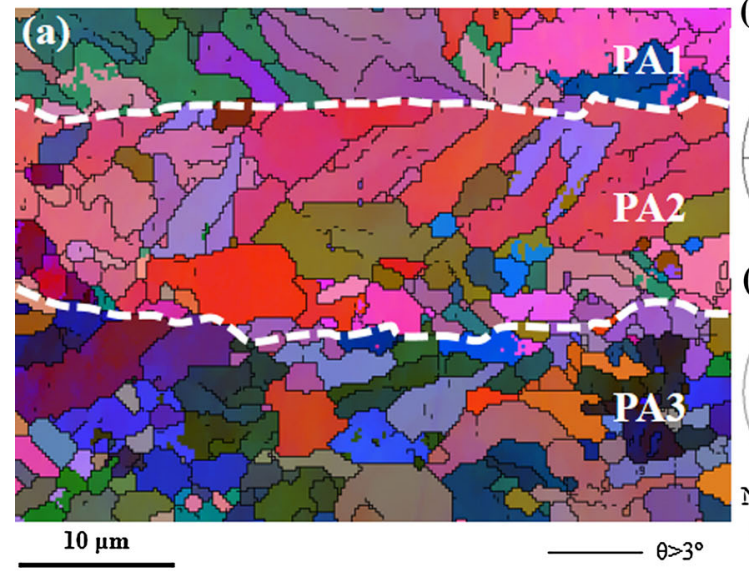

Figure 11 EBSD analysis of specimen with strain2 of 0.5 and cooling rate of $10{ }^{\circ} \mathrm{C} \mathrm{s}^{-1}$ : a all-Euler-angle coloured orientation map (black lines represent boundaries with disorientation angles greater than $3^{\circ}$ and PAGBs are shown by white dashed lines); (b) PA1

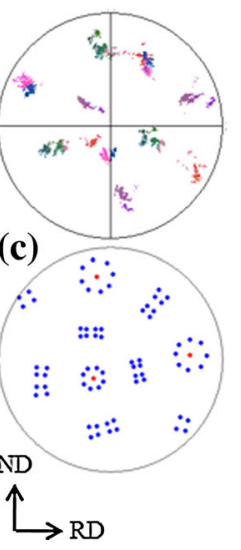

PA2

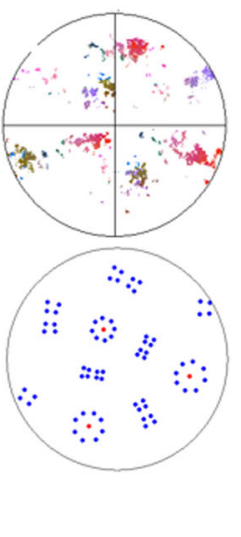

PA3

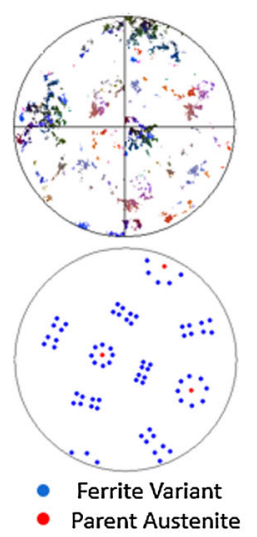

b $\{100\}$ pole figures of the measured ferrite orientations in each parent austenite (PA) grain; c $\{100\}$ pole figures of parent austenite (PA) orientations calculated [60] and their transformation variants, respectively.

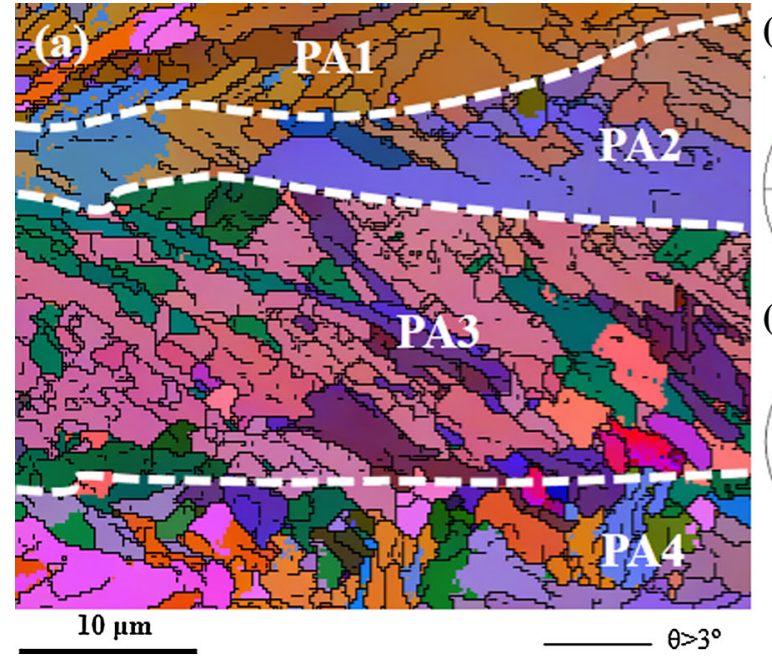

Figure 12 EBSD analysis of specimen with strain2 of 0.5 and cooling rate of $50{ }^{\circ} \mathrm{C} \mathrm{s}^{-1}$ : a all-Euler-angle coloured orientation map (black lines represent boundaries with disorientation angles greater than $3^{\circ}$ and PAGBs are shown by white dashed lines);

possible reasons for the spread of $\alpha$ iron orientations. Under slow cooling rates, there may be some PF/QF grains formed in the final microstructure which do not necessarily follow the K-S orientation relationship with the parent austenite that they grow into. The spreading of $\alpha$ iron orientations may also reflect the austenite orientation spread induced by deformation and the existence of more types of variants promoted by intragranular nucleation.

Based on the above microstructure characteristics, in addition to the requirement of introducing
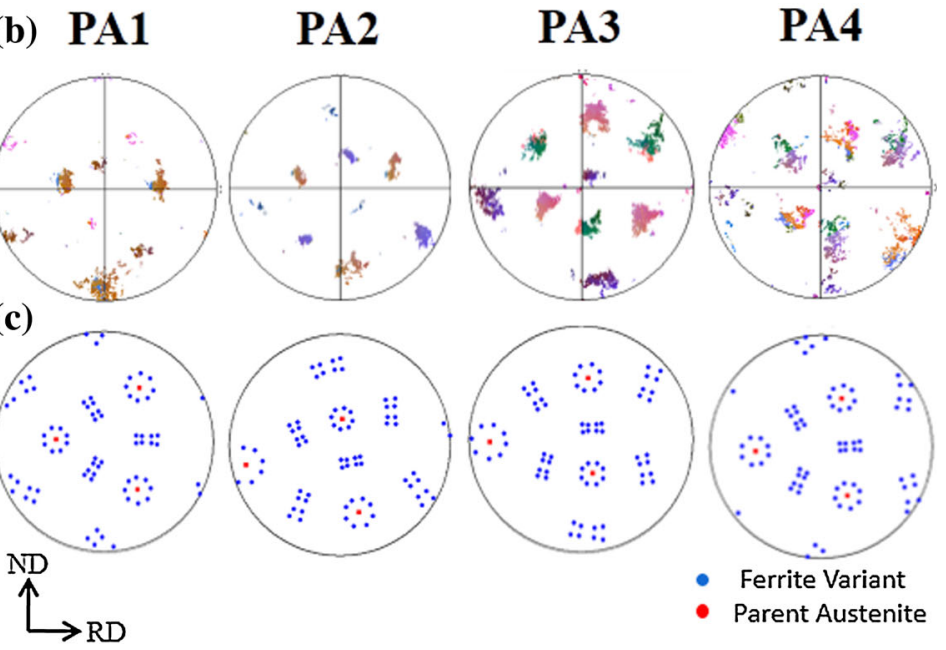

b $\{100\}$ pole figures of the measured ferrite orientations in each parent austenite (PA) grain; c $\{100\}$ pole figures of parent austenite (PA) orientations calculated [60] and their transformation variants, respectively.

intragranular nucleation sites, another condition for the occurrence of the $\mathrm{AF}$ transformation can be hypothesised as below. Since austenite grain boundaries are very potent nucleation sites, BF blocks firstly nucleate on the austenite grain boundaries during cooling. If these BF blocks develop across the whole austenite grain or impinges with other boundary nucleated BF blocks, a BF dominant microstructure is formed. On the other hand, if these boundary nucleated BF blocks are stifled prematurely by certain mechanisms and cannot take up the whole parent 
austenite grain, AF transformation at intragranular nucleation sites happens during the subsequent cooling process. Therefore, suppression of BF laths lengthening should be another requirement for the occurrence of AF transformation.

The possible mechanism suppressing the lengthening of BF laths is also related to the austenite deformation. Displacive transformations involve the coordinated movement of lattice atoms, and such motion of a glissile interface can be suppressed if it encounters strong defects such as austenite grain boundaries or deformation substructures [5]. Less strong defects such as isolated dislocations also retard the progress of such product interfaces but can often be incorporated into the transformation product lattice. These mechanisms indicate that austenite deformation can retard or suppress the advance of displacive transformation interfaces. This retardation of displacive transformations by austenite plastic deformation is called mechanical stabilisation of austenite [5] and has been found for all of the displacive transformations in steels, including Widmanstätten ferrite [63-65], martensite [66, 67] and bainite [68-70].

This mechanical stabilisation effect can be analysed by a model established by balancing the driving stress of interfaces advancing against the resistance stress exerted by dislocations [70]. The resistance stress $\tau$ exerted by deformation introduced dislocations can be expressed as:

$\tau=\frac{G b \rho^{1 / 2}}{8 \pi(1-v)}$

where $G$ is the shear modulus, $v$ the Poisson's ratio, and $\rho$ the dislocation density [71]. The stress $\tau_{T}$ driving the advance of interfaces originates from the chemical free energy change $\Delta G$ of the displacive transformation, $\tau_{T}=\Phi \Delta G$, where $\Phi$ is a constant assumed to be equal to unity. $\Delta G$ varies with transformation temperatures. The motion of the interfaces stops when the driving stress, $\tau_{T}$, is equal to or lower than the resistance stress, $\tau$. The driving stress can be obtained by calculating the chemical free energy change, and based on this driving stress, we can get the lowest dislocation density which is able to suppress the motion of displacive transformation interfaces.

The chemical free energy change of the tested steel in this research was calculated using a thermodynamic calculation software, Thermal-Calc, which accesses thermodynamic data (TCFE6 database) to calculate phase stabilities and free energies. The stored energy due to shape deformation accompanying the bainite transformation is approximately $400 \mathrm{~J} / \mathrm{mol}$ [72] which was subsequently subtracted from the calculation results. The values of the $\mathrm{BF}$ transformation driving force (after the subtraction of $400 \mathrm{~J} / \mathrm{mol}$ stored energy) at different temperatures are shown in Fig. 13a. It can be seen that when temperature is lower than $645^{\circ} \mathrm{C}$, the bainitic transformation is thermodynamically possible for the tested steel.

Based on these driving stress results, the lowest suppression-effective dislocation densities in austenite were calculated using Eq. (1) with an austenite shear modulus of $8 \times 10^{10} \mathrm{~Pa}$, Poisson's ratio 0.27 and Burgers vector $2.52 \times 10^{-10} \mathrm{~m}$ [70]. However, the dislocation density of deformed austenite is difficult to measure. Therefore, the dislocation densities were roughly converted to boundary disorientation angles according to the relationship $b \rho^{1 / 2} \approx \theta$ where $\theta$ is the boundary disorientation angle.

The lowest suppression-effective dislocation densities and corresponding boundary disorientation angles at different temperatures are shown in Fig. 13b. As the temperature increases, for example, from 460 to $550{ }^{\circ} \mathrm{C}$, the lowest suppression-effective boundary disorientation angle increases, from $0.9^{\circ}$ to $2.0^{\circ}$. Regarding the practical sub-grain disorientation angles formed during austenite deformation, in research [73], PSC tests were conducted on a Ni$29.5 \% \mathrm{Fe}-0.01 \% \mathrm{C}-0.02 \% \mathrm{Mn}$ model alloy with an initial grain size of $\sim 50 \mu \mathrm{m}$, deformation temperature of $900{ }^{\circ} \mathrm{C}$, strain rate of $1 \mathrm{~s}^{-1}$ and strains ranging from 0.2 to 0.7 , which are very similar to the experimental conditions in present study. In research [73], the relationship between the average disorientation angle $\left(\theta_{\text {av }}\right)$ and strain $(\varepsilon)$ at $900{ }^{\circ} \mathrm{C}$ was described by a power law equation, $\theta_{\mathrm{av}}=1.77 \varepsilon^{0.23}$. Using this relationship, with a strain of 0.5 in this research, the average sub-grain disorientation angle is $1.5^{\circ}$. As for the disorientation angle distribution, according to the scaling hypothesis $[74,75]$, the distribution functions of the disorientation angles normalised by the average disorientation angles are the same and insensitive to material and strain volume. Based on the distribution scaled shown in research [75], the highest disorientation angle density appears at $\sim 0.7 \theta_{a v}$, which equals $1.1^{\circ}$ with $\theta_{\mathrm{av}}=1.5^{\circ}$. 

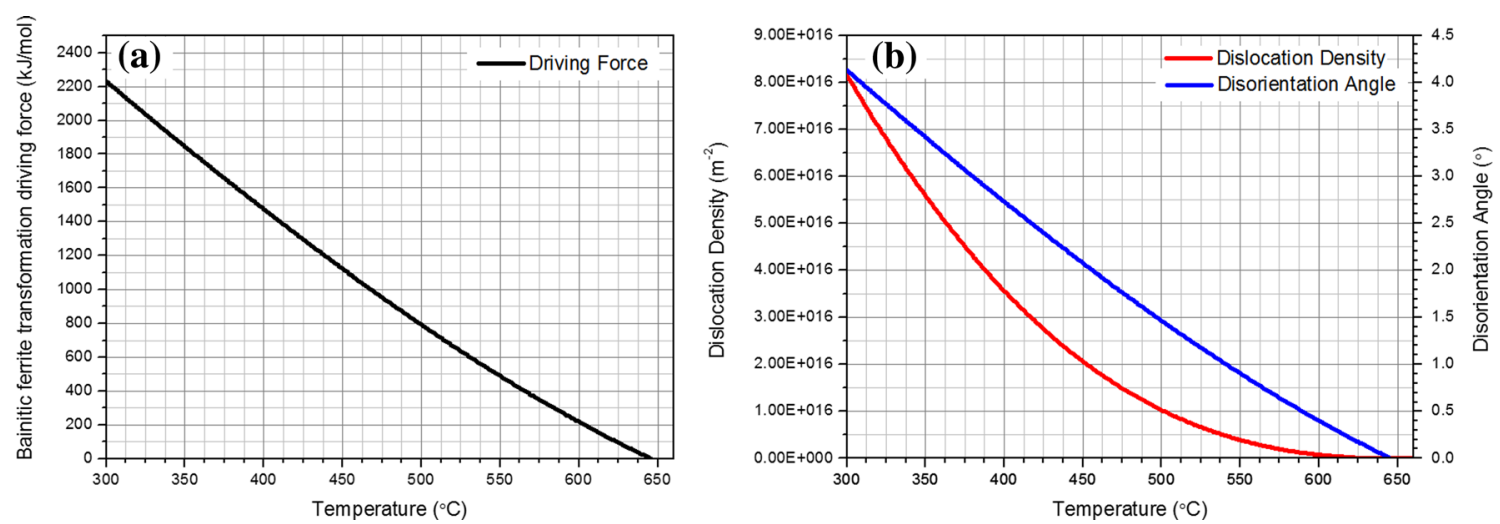

Figure 13 Variation of $\mathbf{a}$ bainitic ferrite transformation driving force and $\mathbf{b}$ the lowest interface motion suppressing dislocation density with corresponding disorientation angle of austenite as a function of transformation temperature.

Therefore, in this study with strain $2=0.5$, lowering the transformation temperature by increasing the cooling rate, the lowest suppression-effective boundary disorientation angle increase, Fig. 13b, and the possibility of the $\mathrm{BF}$ transformation interface being stopped by deformation-induced sub-grain boundaries is reduced, resulting in the transition from $\mathrm{AF}$ to $\mathrm{BF}$ with cooling rate increasing from 10 to $50{ }^{\circ} \mathrm{C} \mathrm{s}^{-1}$. In other words, with the same strain, it is the transformation temperature that determines whether deformation substructures can suppress BF laths lengthening and give room for AF to develop.

Based on the mechanism illustrated above, we can further conceive that if the deformed austenite is cooled very fast from the deformation temperature to room temperature, there should be very few AF laths in the microstructure. Conversely, if the deformed austenite is cooled very fast from the deformation temperature but to a relatively high temperature and then cooled slowly, an AF dominant microstructure should be obtained. To testify these conceptions, another two samples were tested. Both of them underwent the same deformation profile with strain2 $=0.5$, but one of them was water quenched to room temperature after deformation and the other one was fast cooled to $600{ }^{\circ} \mathrm{C}$ from $950{ }^{\circ} \mathrm{C}$ at $100{ }^{\circ} \mathrm{C} \mathrm{s}^{-1}$ and then slowly cooled to $350{ }^{\circ} \mathrm{C}$ at $1{ }^{\circ} \mathrm{C} \mathrm{s}^{-1}$ followed by a water quenching to room temperature. The transformed microstructures of these two samples are shown in Fig. 14. It can be seen clearly that for water quenched sample the microstructure consisted primarily of $\mathrm{BF}$ and martensite with an evident parallel morphology and intragranularly nucleated AF laths can hardly be found. While for the other sample, the transformed microstructure is AF dominant with an irregular arrangement, and this further proves that instead of cooling rates, the transformation temperature is the critical parameter for the occurrence of the $\mathrm{AF}$ transformation.

It is clear that under high cooling rates or low transformation temperatures, intragranular nucleation sites are unable to induce the AF transformation and the transformed microstructure is $\mathrm{BF}$ dominant. For $\mathrm{BF}$ microstructures, austenite deformation can result in a strong variant selection that $\mathrm{BF}$ variants with habit planes parallel to the active slip planes during austenite deformation are favoured [76]. This kind of variant selection can be found in PA2 and PA3 in Fig. 12a. The traces of the lath boundaries on the RD-ND plane are around $32^{\circ}$ away from the RD and based on the Schmid factor analysis for the main ideal texture component of austenite during plane strain compression [73], the traces of active slip planes in the RD-ND plane are $19.5^{\circ}-45^{\circ}$ away from the RD. Therefore, for deformed austenite, with the cooling rate rising from 10 to $50{ }^{\circ} \mathrm{C} \mathrm{s}^{-1}$, due to the increased $\mathrm{BF}$ fraction and the strong $\mathrm{BF}$ variant selection resulted from the austenite deformation, the effective grain size become increasingly large as shown in Fig. 10b.

Some characteristics of the AF microstructure are also in need of further explanation.

(1) Although the BF laths nucleated on PAGBs need to be suppressed to give room for AF to develop, parallel BF laths as shown in Fig. 7b, $c$ do not appear on each PAGB. This is because the deformation strain is not evenly distributed 


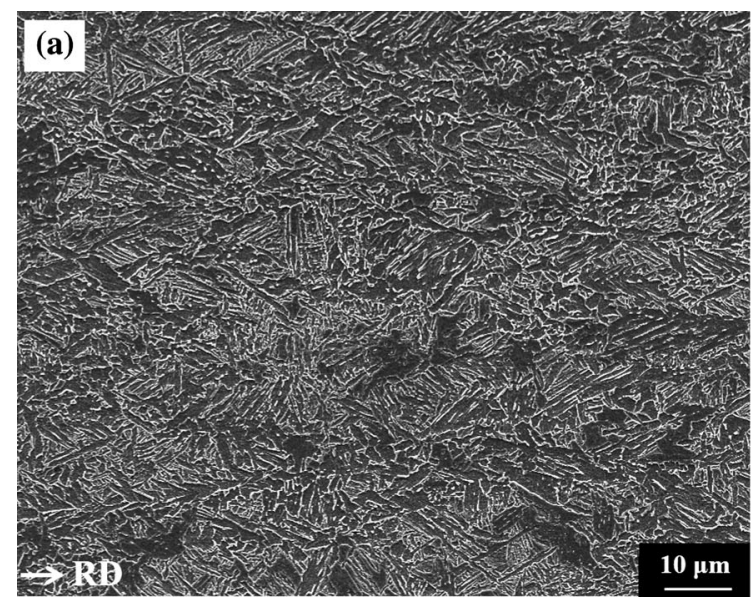

Figure 14 SEM secondary electron micrographs showing the transformed microstructures after different cooling processes with strain 2 of 0.5 : $\mathbf{a}$ water quenched to room temperature; $\mathbf{b}$ cooled at

within each austenite grain. Normally the strain at the austenite grain boundaries is higher than that in the grain interior, and correspondingly, the disorientation angles of sub-grain boundaries near austenite grain boundary will be higher than that in the grain interior. Therefore, PAGB-nucleated BF laths are more likely to be stopped near the austenite grain boundaries without forming large BF packets.

(2) Even in AF dominant microstructures, there are still some long BF laths across the whole parent austenite grains. This can be attributed to the unevenly distributed deformation strains between different parent austenite grains. The differences of deformation-induced substructures between austenite grains with different orientations were reported in research [73].

(3) Although increasing the transformation temperature will promote the mechanical stabilisation effect of austenite deformation and suppress the BF laths more effectively, the maximum possible transformation volume of $\mathrm{AF}$ and $\mathrm{BF}$ will be reduced with the rise of the transformation temperature and finally reaches zero at the bainite transformation start temperature according to the incomplete transformation phenomenon of bainitic transformation [5]. Therefore, the continuous cooling rate and the cooling interrupt temperature need to be selected carefully to stop the lengthening of $\mathrm{BF}$ laths and simultaneously get a high volume fraction of $\mathrm{AF}$ microstructure and continuous

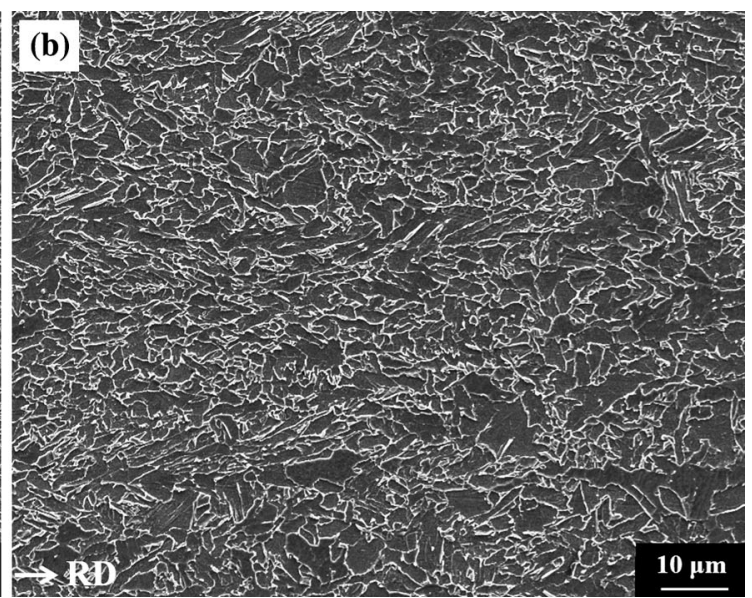

$100{ }^{\circ} \mathrm{C} \mathrm{s}^{-1}$ to $600{ }^{\circ} \mathrm{C}$ and then slowly cooled to $350{ }^{\circ} \mathrm{C}$ at $1{ }^{\circ} \mathrm{C} \mathrm{s}^{-1}$ followed by a water quenching to room temperature.

cooling is more suitable than isothermal holding to get a high volume fraction of AF.

(4) PF transformation happened before both the AF and the BF can consume the nucleation sites on PAGBs and more importantly, the solid solution atoms partitioned from PF grains can stabilise their neighbouring austenite and retard bainite nucleation [77]. Moreover, PF grains formed intragranularly can also suppress the BF laths. Therefore, the formation of $\mathrm{PF}$ grains is beneficial to AF transformation. But the existence of PF grains will undoubtedly lower the strength. Despite the beneficial effect on the AF transformation, the formation of $\mathrm{PF}$ grains is not a prerequisite for AF transformation. In research [12] cooling from austenite deformation temperature $850{ }^{\circ} \mathrm{C}$ to isothermal holding temperature $500-600{ }^{\circ} \mathrm{C}$ at a rate of $75^{\circ} \mathrm{C} \mathrm{s}^{-1}$, AF transformation still occurred without the aid of PF transformation. Similarly, in this research, it can be seen from Fig. 14 that with a cooling rate of $100{ }^{\circ} \mathrm{C} \mathrm{s}^{-1}$ to reduce the interference of $\mathrm{PF}$ transformation, $\mathrm{AF}$ still is the dominant microstructure. In other words, PF/ QF transformation is not a prerequisite for the AF transformation. 


\section{Conclusions}

In this research, to make clear the conditions for the occurrence of AF in HSLA steels, a commercial HSLA steel was used and subjected to plane strain compression tests and continuously cooling with various deformation and cooling parameters. It was found that:

(1) Without austenite deformation, the transformed microstructure gradually changes from granular bainite to lath bainite as the cooling rate increased from 5 to $50{ }^{\circ} \mathrm{C} \mathrm{s}^{-1}$. Both of them nucleate on austenite grain boundaries and acicular ferrite can hardly be found in the transformed microstructures.

(2) Under the same cooling rate of $10^{\circ} \mathrm{C} \mathrm{s}^{-1}$, bainitic ferrite $(\mathrm{BF})$ dominates the microstructure when the austenite is undeformed or slightly deformed, and increasing the austenite deformation, the fraction of acicular ferrite (AF) becomes larger and a transition from $\mathrm{BF}$ to $\mathrm{AF}$ happens. In the meanwhile, the transformed microstructure is refined with the effective grain size reducing from $5.8 \mu \mathrm{m}$ to $2.9 \mu \mathrm{m}$.

(3) Subjected to the same austenite strain, the fraction of AF decreases and $\mathrm{BF}$ becomes more and more dominant with cooling rates increasing from 10 to $50{ }^{\circ} \mathrm{C} \mathrm{s}^{-1}$, which means a transition from AF to BF occurs. At the same time, the transformed microstructure is coarsened with the effective grain size increasing from 2.9 to $3.5 \mu \mathrm{m}$.

(4) Based on the microstructure evolution characteristics, the introduction of intragranular nucleation sites and the suppression of BF laths nucleated on austenite grain boundaries are found as two conditions should be fulfilled for the occurrence of acicular ferrite transformation. Increasing austenite strain can introduce a higher density of dislocations into the austenite, which can act as intragranular nucleation sites. Besides, the deformation substructures can also suppress the lengthening of BF laths through the mechanism of mechanical stabilisation of austenite.

(5) Suppression of BF laths lengthening can only happen under relatively slow cooling rates or higher transformation temperatures. This is because a high cooling rate results in a low transformation temperature which increases the driving stress for transformation interfaces to overcome austenite deformation substructures and finally leads to a BF dominant microstructure.

\section{Acknowledgements}

The authors are grateful for the financial support provided by Companhia Brasileira de Metalurgia e Mineração (CBMM) and the China Scholarship Council (CSC).

\section{Compliance with ethical standards}

Conflict of interest The authors declare that they have no conflict of interest.

Open Access This article is distributed under the terms of the Creative Commons Attribution 4.0 International License (http://creativecommons.org/ licenses/by/4.0/), which permits unrestricted use, distribution, and reproduction in any medium, provided you give appropriate credit to the original author(s) and the source, provide a link to the Creative Commons license, and indicate if changes were made.

\section{References}

[1] Smith Y, Coldren A, Cryderman R (1972) Manganesemolybdenum-niobium acicular ferrite steels with high strength and toughness. In: Toward improved ductility and toughness. Climax Molybdenum Company (Japan) Ltd, Kyoto, pp 119-142

[2] Pontremoli M, Bufalini P, Aprile A, Jannone C (1984) Development of grade API X80 pipeline steel plates produced by controlled rolling. Metals Technol 11(1):504-514

[3] Cryderman R, Coldren A, Bell J, Grozier J (1969) Controlled-cooled structural steels modified with columbium, molybdenum and boron. ASM Trans Q 62(3):561-574

[4] Zhao H, Palmiere EJ (2017) Effect of austenite deformation on the microstructure evolution and grain refinement under accelerated cooling conditions. Metall Mater Trans A 48(7):3389-3399

[5] Bhadeshia HKDH (1992) Bainite in steels. Inst. of Metals, London

[6] Lan L, Chang Z, Kong X, Qiu C, Zhao D (2017) Phase transformation, microstructure, and mechanical properties of 
X100 pipeline steels based on TMCP and HTP concepts. J Mater Sci 52(3):1661-1678. https://doi.org/10.1007/ s10853-016-0459-6

[7] Zhao M, Tang B, Shan Y, Yang K (2003) Role of microstructure on sulfide stress cracking of oil and gas pipeline steels. Metall Mater Trans A 34(5):1089-1096

[8] Zhong Y, Xiao F, Zhang J, Shan Y, Wang W, Yang K (2006) In situ TEM study of the effect of M/A films at grain boundaries on crack propagation in an ultra-fine acicular ferrite pipeline steel. Acta Mater 54(2):435-443

[9] Chiou C, Yang J, Huang C (2001) The effect of prior compressive deformation of austenite on toughness property in an ultra-low carbon bainitic steel. Mater Chem Phys 69(1):113-124

[10] Janzen TS, Horner WN (1998) Alliance pipeline - a design shift in long distance gas transmission. In: Proceedings of the international pipeline conference. ASME, New York

[11] Grimpe F, Meimeth S, Heckmann C, Liessem A, Gehrke A (2005) Development, production and application of heavy plates in grades up to X120. In: 1st international conference "Super-High Strength Steels", Rome, Italy, pp 2-4

[12] Kim YM, Lee H, Kim NJ (2008) Transformation behavior and microstructural characteristics of acicular ferrite in linepipe steels. Mater Sci Eng A 478(1):361-370

[13] Bai D, Yue S, Maccagno T, Jonas J (1998) Effect of deformation and cooling rate on the microstructures of low carbon $\mathrm{Nb}-\mathrm{B}$ steels. ISIJ Int 38(4):371-379

[14] Lee JL, Hon MH, Cheng GH (1987) The intermediate transformation of $\mathrm{Mn}-\mathrm{Mo}-\mathrm{Nb}$ steel during continuous cooling. J Mater Sci 22(8):2767-2777. https://doi.org/10. 1007/BF01086469

[15] Xiao F, Liao B, Shan YY, Qiao GY, Zhong Y, Zhang C, Yang $\mathrm{K}$ (2006) Challenge of mechanical properties of an acicular ferrite pipeline steel. Mater Sci Eng A 431(1):41-52

[16] Xiao F, Liao B, Ren D, Shan Y, Yang K (2005) Acicular ferritic microstructure of a low-carbon $\mathrm{Mn}-\mathrm{Mo}-\mathrm{Nb}$ microalloyed pipeline steel. Mater Charact 54(4-5):305-314

[17] Zhao MC, Yang K, Xiao FR, Shan YY (2003) Continuous cooling transformation of undeformed and deformed low carbon pipeline steels. Mater Sci Eng A 355(1):126-136

[18] Zolotarevskii NY, Zisman A, Panpurin S, Titovets YF, Golosienko S, Khlusova E (2014) Effect of the grain size and deformation substructure of austenite on the crystal geometry of bainite and martensite in low-carbon steels. Met Sci Heat Treat 55(9-10):550-558

[19] Kawata H, Sakamoto K, Moritani T, Morito S, Furuhara T, Maki T (2006) Crystallography of ausformed upper bainite structure in Fe-9Ni-C alloys. Mater Sci Eng A 438:140-144

[20] Malet L, Barnett M, Jacques P, Godet S (2009) Variant selection during the $\gamma$-to- $\alpha \mathrm{b}$ phase transformation in hot- rolled bainitic TRIP-aided steels. Scripta Mater 61(5):520-523

[21] Shewmon PG (1969) Transformations in metals. McGrawHill, New York

[22] Hulka K, Gray J (2001) High temperature processing of line pipe steels. In: Proceedings of the international symposium niobium, pp 587-612

[23] Stalheim DG (2005) The use of high temperature processing (HTP) steel for high strength oil and gas transmission pipeline applications. Iron Steel 40(11):699-704

[24] Sun L, Thomas M, Wynne B, Palmiere E, Mingard K, Roebuck B (2010) Mapping microstructure inhomogeneity using electron backscatter diffraction in $316 \mathrm{~L}$ stainless steel subjected to hot plane strain compression tests. Mater Sci Technol 26(12):1477-1486

[25] Shibata K, Asakura K (1995) Transformation behavior and microstructures in ultra-low carbon steels. ISIJ Int 35(8):982-991

[26] Cizek P, Wynne BP, Davies CHJ, Hodgson PD (2014) The effect of simulated thermomechanical processing on the transformation behavior and microstructure of a low-carbon Mo-Nb linepipe steel. Metall Mater Trans A 46(1):407-425

[27] Shrestha SL, Breen AJ, Trimby P, Proust G, Ringer SP, Cairney JM (2014) An automated method of quantifying ferrite microstructures using electron backscatter diffraction (EBSD) data. Ultramicroscopy 137:40-47

[28] Zhao H, Wynne B, Palmiere E (2017) A phase quantification method based on EBSD data for a continuously cooled microalloyed steel. Mater Charact 123:339-348

[29] Takayama N, Miyamoto G, Furuhara T (2012) Effects of transformation temperature on variant pairing of bainitic ferrite in low carbon steel. Acta Mater 60(5):2387-2396

[30] Zhu K, Barbier D, Iung T (2013) Characterization and quantification methods of complex BCC matrix microstructures in advanced high strength steels. J Mater Sci 48(1):413-423. https://doi.org/10.1007/s10853-012-6756-9

[31] Zhao H, Wynne B, Palmiere E (2017) Effect of austenite grain size on the bainitic ferrite morphology and grain refinement of a pipeline steel after continuous cooling. Mater Charact 123:128-136

[32] Smirnov M, Pyshmintsev IY, Boryakova A (2010) Classification of low-carbon pipe steel microstructures. Metallurgist 54(7):444-454

[33] Yakubtsov I, Boyd J (2001) Bainite transformation during continuous cooling of low carbon microalloyed steel. Mater Sci Technol 17(3):296-301

[34] Kitahara H, Ueji R, Tsuji N, Minamino Y (2006) Crystallographic features of lath martensite in low-carbon steel. Acta Mater 54(5):1279-1288 
[35] Wang W, Yan W, Zhu L, Hu P, Shan Y, Yang K (2009) Relation among rolling parameters, microstructures and mechanical properties in an acicular ferrite pipeline steel. Mater Des 30(9):3436-3443

[36] Kim S, Kim Y, Lim Y, Kim NJ (2006) Relationship between yield ratio and the material constants of the Swift equation. Met Mater Int 12(2):131-135

[37] Fang H, Wang J, Yang Z, Li C, Bo X, Zheng Y (1999) Bainite transformation. Science Press, Beijing

[38] Araki T, Kozasu I, Tankechi H, Shibata K, Enomoto M, Tamehiro H (1992) Atlas for bainitic microstructures. ISIJ, Tokyo

[39] Araki T, Shibata K, Enomoto M (1991) Reviewed concept on the microstructural identification and terminology of low carbon ferrous bainites. Mater Sci Forum 56:275-280

[40] Collins L, Godden M, Boyd J (1983) Microstructures of linepipe steels. Can Metall Q 22(2):169-179

[41] DeVito CPaA (1979) High-strength microalloyed pipe steels resistant to hydrogen-induced failures. In: MiCon 78: optimization of processing, properties, and service performance through microstructural control 672:53

[42] Shang C, Hu L, Yang S, Wang X, Zhao Y, He X (2005) Forming and controlling of the acicular ferrite in low carbon microalloyed steel. Acta Metall Sin 41(5):471-476

[43] Zhao M, Hanamura T, Qiu H, Nagai K, Shan Y-Y, Yang K (2005) Difference in the role of non-quench aging on mechanical properties between acicular ferrite and ferritepearlite pipeline steels. ISIJ Intl 45(1):116-120

[44] Tang Z, Stumpf W (2008) The role of molybdenum additions and prior deformation on acicular ferrite formation in microalloyed $\mathrm{Nb}-\mathrm{Ti}$ low-carbon line-pipe steels. Mater Charact 59(6):717-728

[45] Kim YM, Shin SY, Lee H, Hwang B, Lee S, Kim NJ (2007) Effects of molybdenum and vanadium addition on tensile and charpy impact properties of API X70 linepipe steels. Metall Mater Trans A 38(8):1731-1742

[46] Liu C, Shi L, Liu Y, Li C, Li H, Guo Q (2016) Acicular ferrite formation during isothermal holding in HSLA steel. J Mater Sci 51(7):3555-3563. https://doi.org/10.1007/ s10853-015-9675-8

[47] Olson G, Cohen M (1976) A general mechanism of martensitic nucleation: Part II. FCC $\rightarrow$ BCC and other martensitic transformations. Metall Mater Trans A 7(12):1905-1914

[48] Brooks JW, Loretto MH, Smallman RE (1979) Direct observations of martensite nuclei in stainless steel. Acta Metall 27(12):1839-1847

[49] Olson GB, Cohen M (1972) A mechanism for the straininduced nucleation of martensitic transformations. J Less Common Methods 28(1):107-118
[50] Suezawa M, Cook H (1980) On the nucleation of martensite. Acta Metall 28(4):423-432

[51] Yeddu HK, Lookman T, Saxena A (2013) Strain-induced martensitic transformation in stainless steels: a three-dimensional phase-field study. Acta Mater 61(18):6972-6982

[52] Zhang W, Jin Y, Khachaturyan A (2007) Phase field microelasticity modeling of heterogeneous nucleation and growth in martensitic alloys. Acta Mater 55(2):565-574

[53] Magee CL (1970) The nucleation of martensite. In: Aaronson HI, Zackay VF (eds) Phase Transformations. ASM, Metals Park, pp 115-156

[54] Christian J (1969) The mechanism of phase transformations in crystalline solids. Institute of Metals, London

[55] Shigeta T, Takada A, Terasaki H, Y-i Komizo (2013) The effects of ausforming on variant selection of martensite in Cr-Mo steel. Q J Jpn Weld Soc 31(4):178-182

[56] Yamamoto S, Yokoyama H, Yamada K, Niikura M (1995) Effects of the austenite grain size and deformation in the unrecrystallized austenite region on bainite transformation behavior and microstructure. ISIJ Int 35(8):1020-1026

[57] Yang J, Huang C, Chiou C (1995) The influence of plastic deformation and cooling rates on the microstructural constituents of an ultra-low carbon bainitic steel. ISIJ Intl 35(8):1013-1019

[58] Fujiwara K, Okaguchi S, Ohtani H (1995) Effect of hot deformation on bainite structure in low carbon steels. ISIJ Int 35(8):1006-1012

[59] Díaz-Fuentes M, Gutiérrez I (2003) Analysis of different acicular ferrite microstructures generated in a medium-carbon molybdenum steel. Mater Sci Eng A 363(1):316-324https://doi.org/10.1007/s10853-016-0459-6

[60] Tari V, Rollett A, Beladi H (2013) Back calculation of parent austenite orientation using a clustering approach. J Appl Crystallogr 46(1):210-215

[61] Furuhara T, Kawata H, Morito S, Miyamoto G, Maki T (2008) Variant selection in grain boundary nucleation of upper bainite. Metall Mater Trans A 39(5):1003-1013

[62] Lambert-Perlade A, Gourgues AF, Pineau A (2004) Austenite to bainite phase transformation in the heat-affected zone of a high strength low alloy steel. Acta Mater 52(8):2337-2348

[63] Shipway P, Bhadeshia H (1997) The mechanical stabilisation of Widmanstätten ferrite. Mater Sci Eng A 223(1):179-185

[64] Larn RH, Yang JR (2000) The effect of compressive deformation of austenite on the bainitic ferrite transformation in Fe-Mn-Si-C steels. Mater Sci Eng A 278(1-2):278-291

[65] Larn R, Yang J (1999) The effect of compressive deformation of austenite on the Widmanstätten ferrite transformation in Fe-Mn-Si-C steel. Mater Sci Eng A 264(1):139-150 
[66] Leslie WC, Miller RL (1964) The stabilization of austenite by closely spaced boundaries. ASM Trans Q 57(4):972-979

[67] Machlin ES, Cohen M (1951) Burst phenomenon in the martensitic transformation. Trans AIME 191(9):746-754

[68] Shipway P, Bhadeshia H (1995) Mechanical stabilisation of bainite. Mater Sci Technol 11(11):1116-1128

[69] Singh S, Bhadeshia H (1996) Quantitative evidence for mechanical stabilization of bainite. Mater Sci Technol 12(7):610-612

[70] Chatterjee S, Wang H-S, Yang J, Bhadeshia H (2006) Mechanical stabilisation of austenite. Mater Sci Technol 22(6):641-644

[71] Honeycombe RWK (1969) Plastic deformation of metals. Cambridge University Press, Cambridge

[72] Bhadeshia H (1981) A rationalisation of shear transformations in steels. Acta Metall 29(6):1117-1130

[73] Taylor A, Cizek P, Hodgson P (2012) Orientation dependence of the substructure characteristics in a $\mathrm{Ni}-30 \mathrm{Fe}$ austenitic model alloy deformed in hot plane strain compression. Acta Mater 60(4):1548-1569

[74] Hughes D, Liu Q, Chrzan D, Hansen N (1997) Scaling of microstructural parameters: misorientations of deformation induced boundaries. Acta Mater 45(1):105-112

[75] Hughes D, Chrzan D, Liu Q, Hansen N (1998) Scaling of misorientation angle distributions. Phys Rev Lett 81(21):4664-4667

[76] Miyamoto G, Iwata N, Takayama N, Furuhara T (2012) Variant selection of lath martensite and bainite transformation in low carbon steel by ausforming. J Alloys Compd 577(1):528-532

[77] Babu S, Bhadeshia H (1991) Mechanism of the transition from bainite to acicular ferrite. Mater Trans Jpn Inst Met 32(8):679-688 